February 2015

\title{
The Costs and Benefits of Balanced Budget Rules: Lessons from a Political Economy Model of Fiscal Policy*
}

\begin{abstract}
This paper analyzes the impact of a balanced budget rule that requires that legislators do not run deficits in the political economy model of Battaglini and Coate (2008). It considers both a strict rule which cannot be circumvented and a rule that can be overridden by a super-majority of legislators. A strict rule leads to a gradual but substantial reduction in the level of public debt. In the short run, citizens will be worse off as public spending is reduced and taxes are raised to bring down debt. In the long run, the benefits of a lower debt burden must be weighed against the costs of greater volatility in taxes and less responsive public good provision. In a quantitative version of the model, the long run net benefits are positive but are outweighed by the short run costs. A rule with a super-majority override has no effect on citizen welfare or fiscal policy.
\end{abstract}

\author{
Marina Azzimonti \\ Department of Economics \\ Stony Brook University \\ Stony Brook NY 11794 \\ marina.azzimonti@gmail.com \\ Marco Battaglini \\ Department of Economics \\ Cornell University \\ Ithaca NY 14853 \\ battaglini.m@gmail.com \\ Stephen Coate \\ Department of Economics \\ Cornell University \\ Ithaca NY 14853 \\ sc163@cornell.edu
}

\footnotetext{
*This paper is a revision of our paper "Analyzing the Case for a Balanced Budget Amendment to the US Constitution" which was first circulated in 2008. For research assistance we thank Kazuki Konno, Tim Lin, and Matthew Talbert. For helpful comments and encouragement we thank Marco Bassetto, Narayana Kocherlakota, Nancy Stokey, and seminar participants at Carnegie Mellon University, the LAEF Conference at U.C. Santa Barbara, the Midwest Macroeconomic Meetings at the University of Pennsylvania, the Minnesota Workshop on Macroeconomic Theory, North Carolina State University, the Society for the Advancement of Economic Theory Meetings at Kos, the Society of Economic Dynamics Meetings at Prague, University of Southern California, University of Toronto, the Wallis Conference on Political Economy at the University of Rochester, the Wegman's Conference at the University of Rochester, and the Wharton School.
} 


\section{Introduction}

This paper analyzes the impact of a balanced budget rule (BBR) in the political economy model of fiscal policy developed by Battaglini and Coate (2008) (BC). The BC framework begins with a tax smoothing model of fiscal policy of the form studied by Barro (1979), Lucas and Stokey (1983), and Aiyagari et. al. (2002). It departs from the tax smoothing literature by assuming that policy choices are made by a legislature rather than a benevolent planner. Moreover, it incorporates the friction that legislators can redistribute tax dollars back to their districts via pork-barrel spending. This friction means that equilibrium debt levels are too high implying that, in principle, imposing a BBR has the potential to improve welfare.

We model a BBR as a constitutional requirement that tax revenues must be sufficient to cover spending and the costs of servicing the debt. Thus, budget surpluses are permitted, but not deficits. ${ }^{1}$ We consider both a strict BBR which cannot be circumvented by the legislators and a BBR which can be overridden by a super-majority of legislators. ${ }^{2}$ We study how imposing a BBR impacts government debt, tax rates, spending on public goods, and pork-barrel spending. We also study the impact on citizen welfare. We supplement our qualitative analysis with an analysis of a quantitative version of the model.

Our study is motivated by continuing policy interest in BBRs both in the U.S. and in other countries. $^{3} \quad$ While there is no shortage of policy discussion on the pros and cons of BBRs, there has been remarkably little economic analysis of their likely impact. We believe this reflects the inherent difficulty of developing an analysis that even begins to capture the key trade-offs. Since it is clear that in a world in which policy is set by a benevolent planner a BBR can only distort policy and hurt citizen welfare, one must begin with a political economy model of fiscal policy. Moreover, the model must be sufficiently rich to be able to capture the short and long run consequences of imposing a BBR on policy and welfare. The BC model features both a rich policy

\footnotetext{
1 This is consistent with the balanced budget amendments to the U.S. constitution that have been considered by Congress. As reported in Whalen (1995), the balanced budget amendment considered as part of the Contract with America in 1994 required that "total outlays for any fiscal year do not exceed total receipts for that year". Total receipts are defined as "all receipts of the United States except those derived from borrowing" and total outlays are defined as "all outlays of the United States except those for the repayment of debt principle".

2 The constitutional amendments considered by the U.S. Congress typically allow the BBR to be waived with support from at least $60 \%$ of legislators in both the House and Senate.

3 The desirability of amending the U.S. constitution to require that the federal government operate under a BBR continues to be actively debated. Outside the U.S., Austria, Germany, Italy, Slovenia, Switzerland, and Spain have recently added constitutional BBRs.
} 
space and political economy distortions and thus provides a natural framework in which to seek lessons about the impact of a BBR.

We show that in the BC model imposing a strict BBR after debt has reached (unconstrained) equilibrium levels leads to a gradual reduction in debt. In the quantitative version of the model, the long run reduction in the debt/GDP ratio is $94 \%$. This is surprising because the BBR only restricts legislators not to run deficits and thus one might have expected the debt level to remain constant. The reduction occurs because a BBR, by restricting future policies, increases the expected cost of taxation and makes public savings more valuable as a buffer against future shocks. The reduction in debt means that the interest costs of servicing debt will be lower, reducing pressure on the budget. In the quantitative version, average tax rates become lower and public good provision becomes higher than in the steady state of the unconstrained equilibrium. Pork-barrel spending also becomes higher as debt falls. However, the inability to use debt to smooth taxes, leads to more volatile tax rates and less responsive public good provision.

The impact of imposing a strict BBR on citizen welfare is complex. Initially, citizens experience a reduction in average contemporaneous utility, as legislators reduce public spending and increase taxes to pay down debt. As debt declines, in principle they may or may not be better off. This depends on whether the benefits of a lower debt burden are offset by the costs of more volatile tax rates and less responsive public good provision. In the quantitative version of the model, steady state welfare is actually increased by $3 \%$. However, when account is taken of the short run costs, imposing a strict BBR reduces welfare.

The analysis of a BBR which can be overridden is much more straightforward: we show that imposing a BBR with a super-majority override after debt has reached equilibrium levels will have no effect on fiscal policy or citizen welfare. Such a BBR will only have an effect if imposed at the foundation of the state before debt has risen to equilibrium levels. Intuitively, this is because in the $\mathrm{BC}$ model, once debt has reached equilibrium levels, additional debt will be issued only when it is in the interests of all legislators to do so, rather than just a minimum winning coalition. We argue that this result reflects the stationarity of the $\mathrm{BC}$ model and would not necessarily apply in a growing economy.

The organization of the remainder of the paper is as follows. Section 2 discusses related literature. Section 3 briefly outlines the BC model of fiscal policy. Sections 4 and 5 , the heart of the paper, study the impact of imposing a strict BBR on equilibrium fiscal policies and welfare. 
Section 4 presents the qualitative analysis and Section 5 the quantitative counterpart. Section 6 deals with the case of a BBR with super-majority override. Section 7 discusses the lessons from our findings for the policy debate on BBRs and Section 8 concludes.

\section{Related literature}

This paper contributes to a small literature on BBRs. The bulk of this literature has been devoted to the empirical question of whether the BBRs that are used in practice actually have any effect. The basic issue is whether policy-makers are able to circumvent BBRs. Empirical investigation is facilitated by the fact that BBRs are common at the state level in the U.S. and there is significant variation in the stringency of the different rules. Moreover, this variation is plausibly exogenous since many of the states adopted their BBRs as part of their founding constitutions. ${ }^{4}$ Researchers have studied how this stringency impacts fiscal policy (see, for example, Alt and Lowry (1994), Bayoumi and Eichengreen (1995), Bohn and Inman (1996), Hou and Smith (2006, 2010), Poterba (1994), Rose (2006) and von Hagen (1991)). Importantly, these studies find that stringency does matter for fiscal policy. For example, Poterba (1994) shows that states with more stringent restraints were quicker to reduce spending and/or raise taxes in response to negative revenue shocks than those without. ${ }^{5}$ Researchers have also explored how the stringency of BBRs impacts business cycle fluctuations at the state level, some arguing that greater stringency exacerbates volatility (Levinson (1998)) and others arguing just the opposite (Fatas and Mihov (2006)).

Less work has been devoted to the basic theoretical question of whether, assuming that they will not be circumvented, BBRs are desirable. In the optimal fiscal policy literature, a number of authors point out that optimal policy will typically violate a BBR (see, for example, Lucas and Stokey (1983) and Chari, Christiano and Kehoe (1994)). In the context of the model developed by Chari, Christiano and Kehoe (1994), Stockman (2001) studies how a benevolent government would set fiscal policy under a BBR and quantifies the welfare cost of such a restraint. However, by omitting political economy considerations, none of this work allows for the possibility that a BBR

\footnotetext{
${ }^{4}$ Forty nine of the fifty U.S. states have some type of BBR (Vermont is the exception). Rhode Island was the first state to adopt a BBR in 1842 and thirty six more states adopted them before the end of the nineteenth century. See Savage (1988) for more on the history of BBRs and the importance of the balanced budget philosophy in American politics more generally. Stringency varies because some states prohibit the carrying forward a deficit, while others simply require that the budget must balance ex ante (i.e., when it is initially proposed by the governor and/or passed by the legislature).

${ }^{5}$ For overviews of this research see Inman (1996) and Poterba (1996).
} 
might have benefits. Brennan and Buchanan (1980), Buchanan (1995), Buchanan and Wagner (1977), Keech (1985) and Niskanen (1992) provide some interesting discussion of the political economy reasons for a BBR, but do not provide frameworks in which to evaluate the costs and benefits. Besley and Smart (2007) provide an interesting welfare analysis of BBRs and other fiscal restraints within the context of a two period political agency model. The key issue in their analysis is how having a BBR influences the flow of information to citizens concerning the characteristics of their policy-makers. This issue does not arise in the BC model.

In a precursor to this analysis, Battaglini and Coate (2008) briefly consider the desirability of imposing a constitutional constraint at the foundation of the state that prevents government from either running deficits or surpluses. They present a condition under which citizens will be better off with such a constraint. This condition concerns the size of the economy's tax base relative to the size of the public spending needs. The analysis in this paper goes beyond this initial exploration in four important ways. First, it considers a BBR that allows for budget surpluses and hence public saving or debt reduction. Second, it assumes that the BBR is imposed after debt has reached equilibrium levels rather than at the beginning of time. Third, it develops a quantitative version of the model and provides precise predictions concerning the impact of a BBR. Fourth, it considers a BBR with a super-majority override.

More generally, the paper contributes to a broader literature on fiscal constitutions. A fiscal constitution is a set of rules and procedures that govern the determination of fiscal policies (see, for example, Brennan and Buchanan 1980). It is distinct from a political constitution which sets up the architecture of government and the rules by which policy-makers are selected. The fiscal constitution literature seeks to understand the effectiveness of various rules and procedures in generating good fiscal policies for citizens. In addition to balanced budget rules, it studies tax and spending limits, budgetary procedures, debt limits, and rainy day funds. Rose (2010) provides a useful review of this literature.

\section{The BC model}

\subsection{The economic environment}

A continuum of infinitely-lived citizens live in $n$ identical districts indexed by $i=1, \ldots, n$. The size of the population in each district is normalized to be one. There is a single (nonstorable) 
consumption good, denoted by $z$, that is produced using a single factor, labor, denoted by $l$, with the linear technology $z=w l$. There is also a public good, denoted by $g$, that can be produced from the consumption good according to the linear technology $g=z / p$.

Citizens consume the consumption good, benefit from the public good, and supply labor. Each citizen's per period utility function is

$$
z+A \ln g-\frac{l^{(1+1 / \varepsilon)}}{\varepsilon+1},
$$

where $\varepsilon>0$. The parameter $A$ measures the value of the public good to the citizens. Citizens discount future per period utilities at rate $\delta$.

The value of the public good varies across periods in a random way, reflecting shocks to the society such as wars and natural disasters. Specifically, in each period, $A$ is the realization of a random variable with range $[\underline{A}, \bar{A}]$ and cumulative distribution function $G(A)$. The function $G$ is continuously differentiable and its associated density is bounded uniformly below by some positive constant $\xi>0$, so that for any pair of realizations such that $A<A^{\prime}$, the difference $G\left(A^{\prime}\right)-G(A)$ is at least as big as $\xi\left(A^{\prime}-A\right)$.

There is a competitive labor market and competitive production of the public good. Thus, the wage rate is equal to $w$ and the price of the public good is $p$. There is also a market in risk-free, one period bonds. The assumption of a constant marginal utility of consumption implies that the equilibrium interest rate on these bonds must be $\rho=1 / \delta-1$.

\subsection{Government policies}

The public good is provided by the government. The government can raise revenue by levying a proportional tax on labor income. It can also borrow and lend by selling and buying bonds. Revenues can also be diverted to finance targeted district-specific monetary transfers which are interpreted as (non-distortionary) pork-barrel spending.

Government policy in any period is described by an $n+3$-tuple $\left\{\tau, g, b^{\prime}, s_{1}, \ldots ., s_{n}\right\}$, where $\tau$ is the income tax rate; $g$ is the amount of public good provided; $b^{\prime}$ is the amount of bonds sold; and $s_{i}$ is the transfer to district $i$ 's residents. When $b^{\prime}$ is negative, the government is buying bonds. In each period, the government must also repay the bonds that it sold in the previous period which are denoted by $b$. The government's initial debt level in period 1 is $b_{0}$.

In a period in which government policy is $\left\{\tau, g, b^{\prime}, s_{1}, \ldots, s_{n}\right\}$, each citizen will supply $l^{*}(\tau)=$ 
$(\varepsilon w(1-\tau))^{\varepsilon}$ units of labor. A citizen in district $i$ who simply consumes his net of tax earnings and his transfer will obtain a per period utility of $u(\tau, g ; A)+s_{i}$, where

$$
u(\tau, g ; A)=\frac{\varepsilon^{\varepsilon}(w(1-\tau))^{\varepsilon+1}}{\varepsilon+1}+A \ln g .
$$

Since citizens are indifferent as to their allocation of consumption across time, their lifetime expected utility will equal the value of their initial bond holdings plus the payoff they would obtain if they simply consumed their net earnings and transfers in each period.

Government policies must satisfy three feasibility constraints. ${ }^{6}$ First, tax revenues must be sufficient to cover public expenditures. To see what this implies, consider a period in which the initial level of government debt is $b$ and the policy choice is $\left\{\tau, g, b^{\prime}, s_{1}, \ldots, s_{n}\right\}$. Expenditure on public goods and debt repayment is $p g+(1+\rho) b$, tax revenue is $R(\tau)=n \tau w l^{*}(\tau)$, and revenue from bond sales is $b^{\prime}$. Letting the net of transfer surplus be denoted by

$$
B\left(\tau, g, b^{\prime} ; b\right)=R(\tau)-p g+b^{\prime}-(1+\rho) b,
$$

the constraint requires that $B\left(\tau, g, b^{\prime} ; b\right) \geq \sum_{i} s_{i}$. Second, district-specific transfers must be nonnegative (i.e., $s_{i} \geq 0$ for all $i$ ). Third, the government cannot borrow more than it can repay which requires that $b^{\prime}$ is less than $\bar{b}=\max _{\tau} R(\tau) / \rho$.

\subsection{The political process}

Government policy decisions are made by a legislature consisting of representatives from each of the $n$ districts. One citizen from each district is selected to be that district's representative. Since all citizens have the same policy preferences, the identity of the representative is immaterial and hence the selection process can be ignored. The legislature meets at the beginning of each period. These meetings take only an insignificant amount of time, and representatives undertake private sector work in the rest of the period just like everybody else. The affirmative votes of $q<n$ representatives are required to enact any legislation.

To describe how legislative decision-making works, suppose the legislature is meeting at the beginning of a period in which the current level of public debt is $b$ and the value of the public good

\footnotetext{
${ }^{6}$ There is also an additional constraint that the total amount of private sector income be larger than the amount borrowed by the government. This requires that $\sum_{i} s_{i}+(1+\rho) b+n(1-r) w(\varepsilon w(1-r))^{\varepsilon}$ exceed $b^{\prime}$. Using the budget balance condition for the government, this constraint amounts to the requirement that national income $n w(\varepsilon w(1-r))^{\varepsilon}$ exceed public good spending $p g$. This condition is easily satisfied in the calibration of the model for the U.S. economy presented in Section 4. Thus, in the theoretical analysis, we will assume it is always satisfied.
} 
is $A$. One of the legislators is randomly selected to make the first proposal, with each representative having an equal chance of being recognized. A proposal is a policy $\left\{\tau, g, b^{\prime}, s_{1}, \ldots ., s_{n}\right\}$ that satisfies the feasibility constraints. If the first proposal is accepted by $q$ legislators, then it is implemented and the legislature adjourns until the beginning of the next period. At that time, the legislature meets again with the difference being that the initial level of public debt is $b^{\prime}$ and there is a new realization of $A$. If, on the other hand, the first proposal is not accepted, another legislator is chosen to make a proposal. There are $T \geq 2$ such proposal rounds, each of which takes a negligible amount of time. If the process continues until proposal round $T$, and the proposal made at that stage is rejected, then a legislator is appointed to choose a default policy. The only restrictions on the choice of a default policy are that it be feasible and that it treats districts uniformly (i.e., $s_{i}=s_{j}$ for all $\left.i, j\right)$.

\subsection{Political equilibrium}

Battaglini and Coate study the symmetric Markov-perfect equilibrium of this model. In this type of equilibrium, any representative selected to propose at round $r \in\{1, \ldots, T\}$ of the meeting at some time $t$ makes the same proposal and this depends only on the current level of public debt $(b)$, the value of the public good $(A)$, and the bargaining round $(r)$. Legislators are assumed to vote for a proposal if they prefer it (weakly) to continuing on to the next proposal round. It is assumed, without loss of generality, that at each round $r$ proposals are immediately accepted by at least $q$ legislators, so that on the equilibrium path, no meeting lasts more than one proposal round. Accordingly, the policies that are actually implemented in equilibrium are those proposed in the first round.

\subsection{Characterization of equilibrium}

To understand equilibrium behavior note that to get support for his proposal, the proposer must obtain the votes of $q-1$ other representatives. Accordingly, given that utility is transferable, he is effectively making decisions to maximize the utility of $q$ legislators. It is therefore as if a randomly chosen minimum winning coalition (mwc) of $q$ representatives is selected in each period and this coalition chooses a policy choice to maximize its aggregate utility.

In any given state $(b, A)$, there are two possibilities: either the mwc will provide pork to the districts of its members or it will not. Providing pork requires reducing public good spending or 
increasing taxation in the present or the future (if financed by issuing additional debt). When $b$ and/or $A$ are sufficiently high, the marginal benefit of spending on the public good and the marginal cost of increasing taxation may be too high to make this attractive. In this case, the mwc will not provide pork and the outcome will be as if it is maximizing the utility of the legislature as a whole.

If the mwc does provide pork, it will choose a tax rate-public good-public debt triple that maximizes coalition aggregate utility under the assumption that they share the net of transfer surplus. Thus, $\left(\tau, g, b^{\prime}\right)$ solves the problem:

$$
\begin{gathered}
\max u(\tau, g ; A)+\frac{B\left(\tau, g, b^{\prime} ; b\right)}{q}+\delta E v\left(b^{\prime}, A^{\prime}\right) \\
\text { s.t. } \quad b^{\prime} \leq \bar{b},
\end{gathered}
$$

where $v$ is the continuation value function. The optimal policy is $\left(\tau^{*}, g^{*}(A), b^{*}\right)$ where the tax rate $\tau^{*}$ satisfies the condition that

$$
\frac{1}{q}=\frac{\left[\frac{1-\tau^{*}}{1-\tau^{*}(1+\varepsilon)}\right]}{n}
$$

the public good level $g^{*}(A)$ satisfies the condition that

$$
\frac{A}{g^{*}(A)}=\frac{p}{q}
$$

and the public debt level $b^{*}$ satisfies

$$
b^{*}=\arg \max \left\{\frac{b^{\prime}}{q}+\delta E v\left(b^{\prime}, A^{\prime}\right): b^{\prime} \leq \bar{b}\right\} .
$$

To interpret condition (5) note that $(1-\tau) /(1-\tau(1+\varepsilon))$ measures the marginal cost of taxation the social cost of raising an additional unit of revenue via a tax increase. It exceeds unity whenever the tax rate $(\tau)$ is positive, because taxation is distortionary. Condition (5) therefore says that the benefit of raising taxes in terms of increasing the per-coalition member transfer $(1 / q)$ must equal the per-capita cost of the increase in the tax rate. Condition (6) says that the per-capita benefit of increasing the public good must equal the per-coalition member reduction in transfers it necessitates. Condition (7) says that the level of borrowing must optimally balance the benefits of increasing the per-coalition member transfer with the expected future costs of higher debt next period. We will discuss this condition further below.

The mwc will choose pork if the net of transfer surplus at this optimal policy $B\left(\tau^{*}, g^{*}(A), b^{*} ; b\right)$ is positive. Otherwise the coalition will provide no pork and its policy choice will maximize 
aggregate legislator (and hence citizen) utility. Conveniently, the equilibrium policies turn out to solve a constrained planning problem:

Proposition 1. The equilibrium value function $v(b, A)$ solves the functional equation

$$
v(b, A)=\max _{\left(\tau, g, b^{\prime}\right)}\left\{\begin{array}{c}
u(\tau, g ; A)+\frac{B\left(\tau, g, b^{\prime} ; b\right)}{n}+\delta E v\left(b^{\prime}, A^{\prime}\right): \\
B\left(\tau, g, b^{\prime} ; b\right) \geq 0, \tau \geq \tau^{*}, g \leq g^{*}(A), \& b^{\prime} \in\left[b^{*}, \bar{b}\right]
\end{array}\right\}
$$

and the equilibrium policies $\left\{\tau(b, A), g(b, A), b^{\prime}(b, A)\right\}$ are the optimal policy functions for this program.

The objective function in problem (8) is average citizen utility. A social planner would therefore maximize this objective function without the constraints on the tax rate, public good level and debt. Thus, political determination simply amounts to imposing three additional constraints on the planning problem. The only complication is that the lower bound on debt $b^{*}$ itself depends upon the value function via equation (7) and hence is endogenous.

Given Proposition 1, it is straightforward to characterize the equilibrium policies. Define the function $A^{*}\left(b, b^{\prime}\right)$ from the equation $B\left(\tau^{*}, g^{*}(A), b^{\prime} ; b\right)=0$. Then, if the state $(b, A)$ is such that $A$ is less than $A^{*}\left(b, b^{*}\right)$ the tax-public good-debt triple is $\left(\tau^{*}, g^{*}(A), b^{*}\right)$ and the mwc shares the net of transfer surplus $B\left(\tau^{*}, g^{*}(A), b^{*} ; b\right)$. If $A$ exceeds $A^{*}\left(b, b^{*}\right)$ the budget constraint binds and no transfers are given. The tax-debt pair exceeds $\left(\tau^{*}, b^{*}\right)$ and the level of public good is less than $g^{*}(A)$. The solution in this case can be characterized by obtaining the first order conditions for problem (8) with only the budget constraint binding. The tax rate and debt level are increasing in $b$ and $A$, while the public good level is increasing in $A$ and decreasing in $b$.

The characterization in Proposition 1 takes as fixed the lower bound on debt $b^{*}$ but as we have stressed this is endogenous. Taking the first order condition for problem (7) and assuming an interior solution, we see that $b^{*}$ satisfies

$$
\frac{1}{q}=-\delta E\left[\frac{\partial v\left(b^{*}, A^{\prime}\right)}{\partial b^{\prime}}\right]
$$

This tells us that the marginal benefit of extra borrowing in terms of increasing the per-coalition member transfer must equal the per-capita expected marginal cost of debt. Using Proposition 1 and the Envelope Theorem, it can be shown that:

$$
-\delta E\left[\frac{\partial v\left(b^{*}, A\right)}{\partial b^{\prime}}\right]=\left[G\left(A^{*}\left(b^{*}, b^{*}\right)\right)+\int_{A^{*}\left(b^{*}, b^{*}\right)}^{\bar{A}}\left(\frac{1-\tau\left(b^{*}, A\right)}{1-\tau\left(b^{*}, A\right)(1+\varepsilon)}\right) d G(A)\right] / n .
$$


The intuition is this: in the event that $A$ is less than $A^{*}\left(b^{*}, b^{*}\right)$ in the next period, increasing debt will reduce pork by an equal amount since that is the marginal use of resources. This has a per-capita cost of $1 / n$. By contrast, in the event that $A$ exceeds $A^{*}\left(b, b^{*}\right)$, there is no pork, so reducing debt means increasing taxes. This has a per-capita cost of $(1-\tau) /[n(1-\tau(1+\varepsilon))]$ when the tax rate is $\tau$.

Substituting (10) into (9), observe that since $1 / q>1 / n$, for $(9)$ to be satisfied, $A^{*}\left(b^{*}, b^{*}\right)$ must lie strictly between $\underline{A}$ and $\bar{A}$. Intuitively, this means that the debt level $b^{*}$ must be such that next period's mwc will provide pork with a probability strictly between zero and one.

\subsection{Equilibrium dynamics}

The long run behavior of fiscal policies in the political equilibrium is summarized in the following proposition:

Proposition 2. The equilibrium debt distribution converges to a unique, non-degenerate invariant distribution whose support is a subset of $\left[b^{*}, \bar{b}\right)$. When the debt level is $b^{*}$, the tax rate is $\tau^{*}$, the public good level is $g^{*}(A)$, and a minimum winning coalition of districts receive pork. When the debt level exceeds $b^{*}$, the tax rate exceeds $\tau^{*}$, the public good level is less than $g^{*}(A)$, and no districts receive pork.

In the long run, equilibrium fiscal policies fluctuate in response to shocks in the value of the public good. Legislative policy-making oscillates between periods of pork-barrel spending and periods of fiscal responsibility. Periods of pork are brought to an end by high realizations in the value of the public good. These trigger an increase in debt and taxes to finance higher public good spending and a cessation of pork. Once in the regime of fiscal responsibility, further high realizations of $A$ trigger further increases in debt and higher taxes. Pork returns only after a suitable sequence of low realizations of $A$. The larger the amount of debt that has been built up, the greater the expected time before pork re-emerges.

Figure 1 illustrates the dynamic evolution of debt under the assumption that there are just two public good shocks, high and low, denoted $A_{H}$ and $A_{L}$. The horizontal axis measures the initial debt level $b$ and the vertical the new level $b^{\prime}$. The dashed line is the $45^{\circ}$ line. The Figure depicts the two policy functions $b^{\prime}\left(b, A_{H}\right)$ and $b^{\prime}\left(b, A_{L}\right)$. In the first period, given the initial debt level $b_{0}$, debt jumps up to $b^{*}$ irrespective of the value of the shock. In the second period, debt remains at $b^{*}$ if the shock is low, but increases if the shock is high. It continues to increase for 


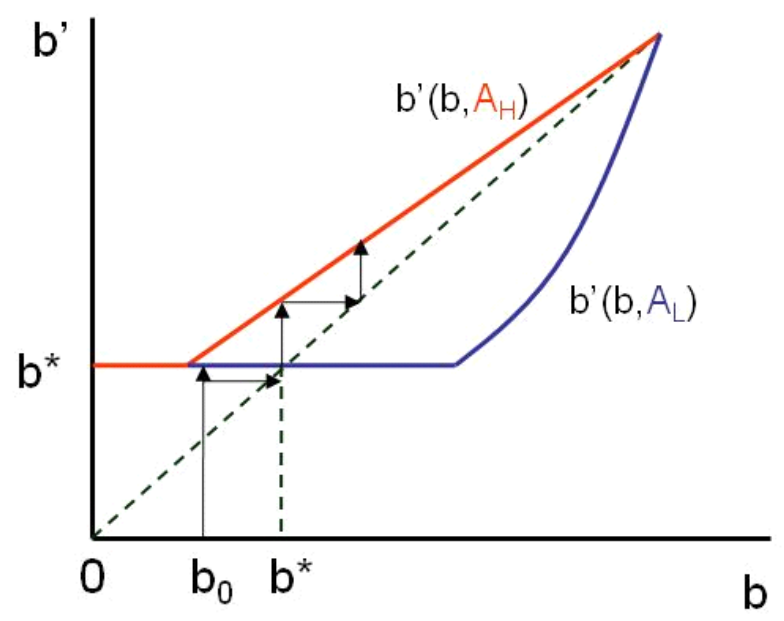

Figure 1: Evolution of debt

as long as the shock is high. When the shock becomes low, debt starts to decrease, eventually returning to $b^{*}$ after a sufficiently long sequence of low shocks.

The debt level $b^{*}$ plays a key role in equilibrating the system. If it is positive, the economy is in perpetual debt, with the extent of debt spiking up after a sequence of high values of the public good. When it is negative, the government will have positive asset holdings at least some of the time. The key determinant of $b^{*}$ is the size of the tax base as measured by $R\left(\tau^{*}\right)$ relative to the economy's desired public good spending as measured by $\mathrm{pg}^{*}(A)$. The greater the relative size of the tax base, the larger is the debt level chosen when the mwc engages in pork-barrel spending. In what follows we will assume that $b^{*}$ is positive which is the empirically relevant case for the U.S. economy.

It is instructive to compare the equilibrium behavior with the planning solution for this economy. The latter is obtained by solving problem (8) without the lower bound constraints on taxes and debt, and the upper bound constraint on public goods. The solution involves the government gradually accumulating sufficient bonds so as to always be able to finance the Samuelson level of the public good solely from the interest earnings. Thus, in the long run, the tax rate is equal to zero. In each period, excess interest earnings are rebated back to citizens via a uniform transfer. 


\section{The impact of a strict BBR: qualitative analysis}

We are now ready to analyze the impact of imposing a strict BBR on the economy. We model a strict $\mathrm{BBR}$ as a requirement that tax revenues must always be sufficient to cover spending and the costs of servicing the debt. If the initial level of debt is $b$, this requires that

$$
R(\tau) \geq p g+\sum_{i} s_{i}+\rho b
$$

Given the definition of $B\left(\tau, g, b^{\prime} ; b\right)$ (see (3)), a BBR is equivalent to adding, in each period, the feasibility constraint that $b^{\prime} \leq b$; i.e., that debt cannot increase. Thus, under a BBR, next period's feasible debt levels are determined by this period's debt choice. In particular, if debt is paid down in the current period, that will tighten the debt constraint in the next period.

\subsection{Equilibrium under a strict BBR}

Under a BBR, the equilibrium will still have a recursive structure. Let $\left\{\tau_{c}(b, A), g_{c}(b, A), b_{c}^{\prime}(b, A)\right\}$ denote the equilibrium policies under the constraint and $v_{c}(b, A)$ the value function. As in the unconstrained equilibrium, in any given state $(b, A)$, either the mwc will provide pork to the districts of its members or it will not. If the mwc does provide pork, it will choose a tax-public good-debt triple that maximizes coalition aggregate utility under the assumption that they share the net of transfer surplus. Thus, $\left(\tau, g, b^{\prime}\right)$ solves the problem:

$$
\begin{gathered}
\max u(\tau)+A \ln g+\frac{B\left(\tau, g, b^{\prime} ; b\right)}{q}+\delta E v_{c}\left(b^{\prime}, A^{\prime}\right) \\
\text { s.t. } \quad b^{\prime} \leq b .
\end{gathered}
$$

The optimal policy is $\left(\tau^{*}, g^{*}(A), b_{c}^{*}(b)\right)$ where the tax rate $\tau^{*}$ and public good level $g^{*}(A)$ are as defined in (5) and (6), and the public debt level $b_{c}^{*}(b)$ satisfies

$$
b_{c}^{*}(b) \in \arg \max \left\{\frac{b^{\prime}}{q}+\delta E v_{c}\left(b^{\prime}, A^{\prime}\right): b^{\prime} \leq b\right\} .
$$

As in the case without a BBR, if the mwc does not provide pork, the outcome will be as if it is maximizing the utility of the legislature as a whole. Following the logic of Proposition 1, we obtain:

Proposition 3. Under a strict BBR, the equilibrium value function $v_{c}(b, A)$ solves the functional 
equation

$$
v_{c}(b, A)=\max _{\left(\tau, g, b^{\prime}\right)}\left\{\begin{array}{c}
u(\tau)+A \ln g+\frac{B\left(\tau, g, b^{\prime} ; b\right)}{n}+\delta E v_{c}\left(b^{\prime}, A^{\prime}\right): \\
B\left(\tau, g, b^{\prime} ; b\right) \geq 0, \tau \geq \tau^{*}, g \leq g^{*}(A), \& b^{\prime} \in\left[b_{c}^{*}(b), b\right]
\end{array}\right\}
$$

and the equilibrium policies $\left\{\tau_{c}(b, A), g_{c}(b, A), b_{c}^{\prime}(b, A)\right\}$ are the optimal policy functions for this program.

As in Proposition 1, the equilibrium can be expressed as a particular constrained planner's problem. There are two key differences created by the BBR. First, there is an additional constraint on debt - an upper bound, $b^{\prime} \leq b$. Second, the endogenous lower bound on debt $b_{c}^{*}(b)$ will be a function of $b$. Because of these two features, the set of feasible policies is now state dependent as well as endogenous. Determining the shape of the function $b_{c}^{*}(b)$ will be crucial to the analysis of the dynamics and the steady state of the equilibrium. Before turning to this, however, note that we can use Proposition 3 to characterize the equilibrium policies for a given function $b_{c}^{*}(b)$. If $A$ is less than $A^{*}\left(b, b_{c}^{*}(b)\right)$ the tax-public good-debt triple is $\left(\tau^{*}, g^{*}(A), b_{c}^{*}(b)\right)$ and the mwc shares the net of transfer surplus $B\left(\tau^{*}, g^{*}(A), b ; b_{c}^{*}(b)\right)$. If $A$ is greater than $A^{*}\left(b, b_{c}^{*}(b)\right)$ the budget constraint binds and no transfers are given. The tax rate exceeds $\tau^{*}$, the level of public good is less than $g^{*}(A)$, and the debt level exceeds $b_{c}^{*}(b)$. In this case, the solution can be characterized by solving problem (13) with only the budget constraint binding and the constraint that $b^{\prime} \leq b$.

\subsection{Characterization of the function $b_{c}^{*}(b)$}

The function $b_{c}^{*}(b)$ tells us, for any given initial $b$, the debt level that the mwc will choose when it provides pork. To understand what $b_{c}^{*}(b)$ is, it is first useful to understand what it cannot be. Suppose that the expected value function $E v_{c}\left(b, A^{\prime}\right)$ were strictly concave (as is the case without a BBR). Then the objective function of the maximization problem in (12) would also be strictly concave and there would be a unique $\widehat{b}$ such that $b_{c}^{*}(b)=\min \{\widehat{b}, b\}$. Thus, for any $b$ larger than $\widehat{b}$, whenever the mwc chooses to provide pork, it would choose the debt level $\widehat{b}$. If this were the case, however, a contradiction would emerge. To see why, note that for initial debt levels $b$ below $\widehat{b}$, the BBR would always be binding so that $b_{c}^{\prime}(b, A)=b$ for all $A$. On the other hand, for debt levels above $\widehat{b}$, there will be states $A$ in which the $\mathrm{BBR}$ will not bind so that $b_{c}^{\prime}(b, A)<b$. This

means that when $b$ is below $\widehat{b}$, a marginal reduction of debt would be permanent: all future mwcs would reduce debt by the same amount. By contrast, for $b$ above $\widehat{b}$, a marginal reduction in debt 
would have an impact on the following period, but it would affect the remaining periods only in the states in which the BBR is binding. Indeed, when the BBR is not binding, $b_{c}^{*}(b)$ would equal $\widehat{b}$, and so would be independent of $b$. It follows that the marginal benefit of reducing debt to the left of $\widehat{b}$ would be higher than the marginal benefit of decreasing debt to the right of $\widehat{b}$. But this contradicts the assumption that the expected value function $E v_{c}\left(b, A^{\prime}\right)$ is strictly concave.

The essential problem with a $b_{c}^{*}(b)$ function of the form $\min \{\widehat{b}, b\}$ is that the marginal effect of $b$ on $b_{c}^{*}(b)$ changes too abruptly at $\widehat{b}$, from one to zero. In equilibrium, the debt level the mwc chooses when it provides pork and the BBR is not binding must change more smoothly. This is not possible when the expected value function is strictly concave, because the maximization problem in (12) has a unique solution which allows no flexibility in choosing $b_{c}^{*}(b)$. If the equilibrium expected value function is concave, therefore, it must be weakly concave. Weak concavity does not pose the same problem since it allows for the possibility that there are a range of debt levels that solve the maximization problem in (12). Suppose this is the case and let $b_{0}$ denote the smallest of these and $b_{1}$ the largest; that is,

$$
b_{0}=\min \arg \max \left\{\frac{b^{\prime}}{q}+\delta E v_{c}\left(b^{\prime}, A^{\prime}\right)\right\},
$$

and

$$
b_{1}=\max \arg \max \left\{\frac{b^{\prime}}{q}+\delta E v_{c}\left(b^{\prime}, A^{\prime}\right)\right\} .
$$

Then any point in $\left[b_{0}, b_{1}\right]$ will solve the maximization problem in (12). If the initial debt level $b$ is smaller than $b_{0}$, then we must have $b_{c}^{*}(b)=b$. But if the initial debt level $b$ exceeds $b_{0}$ then the associated $b_{c}^{*}(b)$ could be any point in the interval $\left[b_{0}, \min \left\{b, b_{1}\right\}\right]$. This extra flexibility suggests that there may exist a function $b_{c}^{*}(b)$ which guarantees that the expected value function is indeed weakly concave. Fortunately, this is not only the case, but there exists a unique such function.

To make all this more precise, define an equilibrium under a strict BBR to be well-behaved if (i) the expected value function is concave and differentiable everywhere, and (ii) the function $b_{c}^{*}(b)$ is non-decreasing and differentiable everywhere. In addition, let $\left(\tau_{b}(A), g_{b}(A)\right)$ be the tax rate and public good level that solve the static maximization problem

$$
\max _{(\tau, g)}\left\{u(\tau)+A \ln g+\frac{B(\tau, g, b, b)}{n}: B(\tau, g, b, b) \geq 0\right\} .
$$

Then we have: 
Proposition 4. There exists a unique well-behaved equilibrium under a strict BBR. The associated function $b_{c}^{*}(b)$ is given by:

$$
b_{c}^{*}(b)=\left\{\begin{array}{cc}
b_{0} & \text { if } b \leq b_{0} \\
f(b) & \text { if } b \in\left(b_{0}, b_{1}\right) \\
f\left(b_{1}\right) & \text { if } b \geq b_{1}
\end{array},\right.
$$

where the point $b_{0}$ solves the equation

$$
G\left(A^{*}\left(b_{0}, b_{0}\right)\right)+\int_{A^{*}\left(b_{0}, b_{0}\right)}^{\bar{A}}\left(\frac{1-\tau_{b_{0}}(A)}{1-\tau_{b_{0}}(A)(1+\varepsilon)}\right) d G(A)=\frac{n}{q}
$$

the function $f(b)$ solves the differential equation

$$
\begin{gathered}
\frac{n}{q}=G\left(A^{*}(b, f(b))\right)\left[1-\frac{d f(b)}{d b} \delta\left(1-\frac{n}{q}\right)\right] \\
+\left(\frac{n}{q}\right)(1-\delta) G\left(A^{*}(b, b)\right)-\left(\frac{n}{q}\right) G\left(A^{*}(b, f(b))\right)+\int_{A^{*}(b, b)}^{\bar{A}}\left(\frac{1-\tau_{b}(A)}{1-\tau_{b}(A)(1+\varepsilon)}\right) d G(A)(1-\delta)+\delta \frac{n}{q}
\end{gathered}
$$

with initial condition $f\left(b_{0}\right)=b_{0}$, and the point $b_{1}$ solves the equation

$\frac{n}{q}(1-\delta)=\frac{n}{q}(1-\delta) G\left(A^{*}\left(b_{1}, b_{1}\right)\right)-\left(\frac{n}{q}-1\right) G\left(A^{*}\left(b_{1}, f\left(b_{1}\right)\right)\right)+\int_{A^{*}\left(b_{1}, b_{1}\right)}^{\bar{A}}\left(\frac{1-\tau_{b_{1}}(A)}{1-\tau_{b_{1}}(A)(1+\varepsilon)}\right) d G(A)(1-\delta)$.

Proof: See Appendix A.

The function $b_{c}^{*}(b)$ is tied down by the requirement that the objective function in the maximization problem (12) must be constant on the interval $\left[b_{0}, b_{1}\right]$. In a well-behaved equilibrium, this implies that $-\delta E \partial v_{c}\left(b^{\prime}, A^{\prime}\right) / \partial b^{\prime}=1 / q$. Since the derivative of the expected value function depends upon the function $b_{c}^{*}(b)$ and its derivative, this implies that $b_{c}^{*}(b)$ satisfies a differential equation with appropriate end-point conditions. This differential equation and its end-points are spelled out in Proposition 4 and derived in its proof.

Figure 2 illustrates the equilibrium function $b_{c}^{*}(b)$. The figure highlights two key properties of this function that will govern the dynamic behavior of the equilibrium. The first property is that $b_{0}$ is strictly less than the level of debt that is chosen by the mwc when it provides pork in the unconstrained case (i.e., $b^{*}$ ). This is immediate from a comparison of (10) and (18). The second is that for any initial debt level $b$ larger than $b_{0}, b_{c}^{*}(b)$ is less than $b$. This follows from the facts that $b_{c}^{*}\left(b_{0}\right)=b_{0}$ and $d b_{c}^{*}(b) / d b$ is less than 1 for $b$ larger than $b_{0}$. 


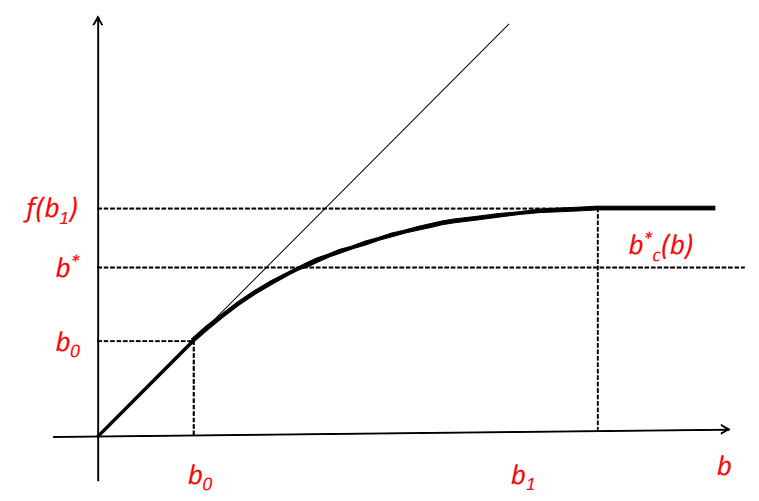

Figure 2: The lower bound $b_{c}^{*}(b)$.

\subsection{Dynamics and steady state}

We now turn to the dynamics. Since in the unconstrained equilibrium, debt must lie in the interval $\left[b^{*}, \bar{b}\right)$, we assume that when the BBR is imposed the initial debt level is in this range. We now have:

Proposition 5. Suppose that a strict BBR is imposed on the economy when the debt level is in the range $\left[b^{*}, \bar{b}\right)$. Then, in a well-behaved equilibrium, debt will converge monotonically to a steady state level $b_{0}$ smaller than $b^{*}$. At this steady state level $b_{0}$, when the value of the public good is less than $A^{*}\left(b_{0}, b_{0}\right)$, the tax rate will be $\tau^{*}$, the public good level will be $g^{*}(A)$, and a mwc of districts will receive pork. When the value of the public good is greater than $A^{*}\left(b_{0}, b_{0}\right)$, the tax rate will be $\tau_{b_{0}}(A)$, the public good level will be $g_{b_{0}}(A)$, and no districts will receive pork.

Proof: See Appendix A.

To understand this result, note first from Propositions 3 and 4 that $b_{c}^{\prime}\left(b_{0}, A\right)=b_{0}$ for all $A$ so that $b_{0}$ is a steady state. The key step is therefore to show that the equilibrium level of debt must converge down to the level $b_{0}$. Since debt can never increase, this requires ruling out the possibility that debt gets "stuck" before it gets down to $b_{0}$. This is done by showing that for any debt level $b$ greater than $b_{0}$, the probability that debt remains at $b$ converges to zero as the number of periods goes to infinity.

Figure 3 illustrates what happens to debt in the two shock case depicted in Figure 1. The Figure depicts the two policy functions $b_{c}^{\prime}\left(b, A_{H}\right)$ and $b_{c}^{\prime}\left(b, A_{L}\right)$. When the shock is high, the 


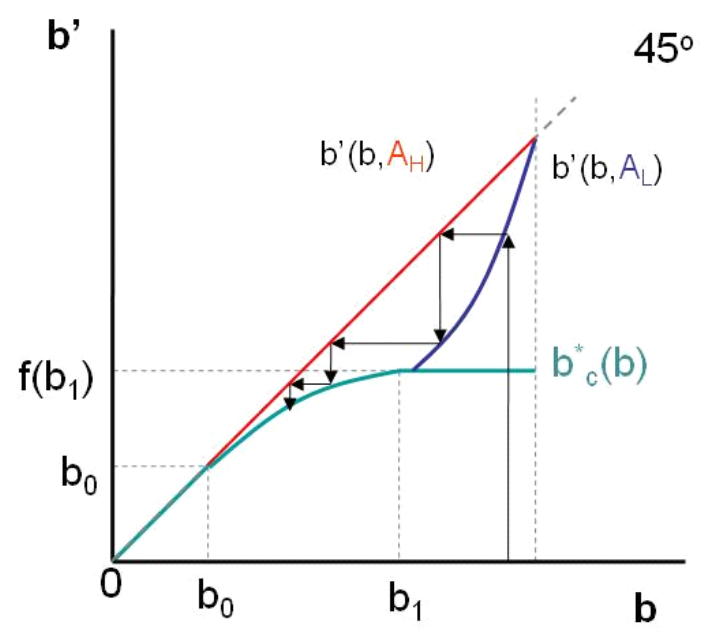

Figure 3: Evolution of debt under a BBR

constraint that debt cannot increase is binding and hence $b_{c}^{\prime}\left(b, A_{H}\right)=b$ for all $b \geq b_{0}$. When the shock is low, however, the constraint is not binding and the mwc finds it optimal to pay down debt. Given an initial debt level exceeding $b^{*}$, debt remains constant as long as the shock is high. When the shock is low, debt starts to decrease. Once it has decreased, it can never go up because of the BBR constraint. Debt converges down to the new steady state level of $b_{0}$.

We can now use Proposition 5 to compare policies at the new steady state with long run policies in the unconstrained equilibrium.

Proposition 6. At the steady state debt level $b_{0}$, the average primary surplus is lower than the long run average primary surplus in the unconstrained equilibrium. In addition, the average level of pork-barrel spending is higher.

Proof: See Appendix A.

Recall that the primary surplus is the difference between tax revenues and public spending other than interest payments. Thus, the first part of this result implies that steady state average tax revenues must be lower under a BBR and/or average public spending must be higher. It should be stressed, however, that this result only refers to the long run. In the transition to the new steady state, at least initially, taxes will be higher and public good spending will be lower as revenues are used to reduce debt. 
The above analysis provides a reasonably complete picture of how imposing a BBR will impact fiscal policy in the $\mathrm{BC}$ model. However, we are also interested in the impact on citizens' welfare. When it is first imposed, it seems likely that a BBR will reduce contemporaneous utility. When $A$ is low, instead of transfers being paid out to the citizens, debt will be being paid down. When $A$ is high, the increase in taxes and reduction in public goods will be steeper than would be the case if the government could borrow. Thus, in either case, citizen welfare should be lower. As debt falls, the picture becomes less clear. On the one hand, citizens gain from the higher average public spending levels and/or lower taxes resulting from the smaller debt service payments. On the other hand, the government's ability to smooth tax rates and public good levels by varying the debt level is lost. Thus, there is a clear trade-off whose resolution will depend on the parameters. The welfare issue is therefore fundamentally a quantitative question and to resolve it we need to turn to a calibrated model.

\section{The impact of a strict BBR: quantitative analysis}

We now study the impact of imposing a strict BBR in a quantitative version of the model. To guide our choice of some of the parameters, we use data from the U.S. from the period 1940-2013. ${ }^{7}$ We first explain how we calibrate the model and then describe the impact of a BBR.

\subsection{Parametrization}

The "state-space" of the BC model is the set of $(b, A)$ pairs such that $b \leq \bar{b}$ and $A \in[\underline{A}, \bar{A}]$. We discretize this state-space by assuming that the preference shock $A$ belongs to a finite set $\mathcal{A}=\left\{A_{1}, \ldots, A_{I}\right\}$ and requiring that the debt level $b$ belongs to the finite set $\mathcal{B}=\left\{b_{1}, \ldots, b_{u}\right\}$. We assume that the lowest debt level $b_{1}$ is equal to the level that a planner would choose in the long run; that is, $b_{1}=-p g_{S}\left(A_{I}\right) / \rho$ where $g_{S}\left(A_{I}\right)$ is the Samuelson level of the public good associated with the maximal shock $A_{I}$. We will discuss how the maximum debt level $b_{u}$ is chosen below.

We normalize the number of districts to $n=100$. Consistent with Cooley and Prescott (1995), we set the discount factor $\delta$ equal to 0.95 . This implies that the annual interest rate on bonds $\rho$ is 5.26\%. Following Aiyagari et. al. (2002) and consistent with the measure used in Greenwood, Hercowitz and Huffman (1988) for a similar disutility of labor function, we assume the elasticity

\footnotetext{
7 Barshegyan, Battaglini and Coate (2013) develop a quantitative version of the BC model in which persistent productivity shocks (as opposed to shocks in the value of the public good) are the driver of fiscal policy. This paper's numerical effort complements their work.
} 
of labor supply $\varepsilon$ is equal to 2 . The wage rate $w$ is normalized so that the value of GDP when the tax rate is $\tau^{*}$ is 100 . This implies a value of $w$ equal to 0.72 . Finally, the price of the public good $p$ is set equal to 1 .

In terms of the shock structure, we assume that in any period, the economy can be in one of two regimes: "ordinary times" or "extraordinary times". The former captures shocks to spending that occurred mostly in the post-war period (including medium size wars such as Vietnam and Iraq), while the latter tries to capture the extraordinary expenditure levels that occurred during World War II. The probability of being in extraordinary times is set equal to $4.1 \%$. This is because there were three years during our 74 year sample (the World War II years 1942-44) in which government spending was particularly large. It follows that the economy is in ordinary times $95.9 \%$ of the time. In ordinary times, $A$ is log-normally distributed with mean $\mu$ and variance $\sigma^{2}$, so that $\log (A) \sim N\left(\mu, \sigma^{2}\right)$. In extraordinary times, $\log (A)$ is equal to $\mu_{e}>\mu$ implying that the demand for public good provision (i.e., defense) is higher. The assumption that there is no volatility in $A$ during extraordinary times is just made for simplicity. In ordinary times, the shocks are discretized using Tauchen's method.

The remaining five parameters - those determining the shock distribution $\mu, \mu_{e}$, and $\sigma$; the required number of votes needed for a proposal to be approved by the legislature $q$; and the upper bound on debt $b_{u}$-are chosen so that the simulated version of the model matches five target moments in the data. While it may seem natural to set $q$ equal to $51 \%$, in the U.S. federal context super-majority approval of budgets will typically be necessary to overcome the threats of presidential vetos or Senate filibusters. Rather than trying to guess an appropriate value based on institutional considerations, we decided to infer $q$ from the data. We choose to calibrate $b_{u}$ rather than setting it equal to the theoretical upper bound on debt $\bar{b}=\max _{\tau} R(\tau) / \rho$ because the latter strategy creates difficulties matching all the moments. In particular, the average debt/GDP ratio predicted by the model is too high. We think that this reflects the fact that the theoretical upper bound is unrealistically high. More specifically, since repaying $\bar{b}$ would imply setting all future public good provision equal to zero, we suspect that the government would in fact default if saddled with this amount of debt.

The first two targets are the mean and variance of government spending as a proportion of GDP during ordinary times $\left(\mathrm{GS}_{o} / \mathrm{GDP}\right)$. The third is the mean of government spending as a proportion of GDP during extraordinary times $\left(\mathrm{GS}_{e} / \mathrm{GDP}\right)$. The fourth target is the average ratio 
of government debt to GDP (Debt/GDP) and the fifth is the maximum Debt/GDP ratio observed in the sample. All the moments used are constructed from the Historical Tables compiled by the Office of Management and Budget. ${ }^{8}$

Our five parameters are chosen so that the model generates, under the numerical approximation to the invariant distribution of policies, close to the same values of our five target moments that are observed in the data. ${ }^{9}$ The resulting values are listed in Table $1 .{ }^{10}$

\begin{tabular}{cclr}
\hline \multicolumn{4}{c}{ Calibrated Parameters } \\
Parameter & Parameter value & Target & Target value \\
\hline \hline$\mu$ & & & \\
\hline \hline & -1.090 & $\operatorname{mean}\left(\mathrm{GS}_{\mathrm{o}} / \mathrm{GDP}\right)$ & $17.1 \%$ \\
$\mu_{\mathrm{e}}$ & 0.566 & st. dev.(GS $/$ GDP) & $2.6 \%$ \\
$\mathrm{q}$ & -0.144 & $\operatorname{mean}\left(\mathrm{GS}_{\mathrm{e}} / \mathrm{GDP}\right)$ & $40 \%$ \\
$\mathrm{~b}_{\mathrm{u}}$ & 56.6 & $\operatorname{mean}(\mathrm{Debt} / \mathrm{GDP})$ & $57 \%$ \\
\hline
\end{tabular}

Notes: Data is obtained from the Historical Tables compiled by the Office of Management and Budget (White House). The sample period is 1940-2013. The variable $G S$ denotes government spending (Total Outlays at the federal level, net of interest payments), $o$ refers to "ordinary times" while the subscript $e$ indicates "extraordinary times" (the World War II years).

Table 1: Model Parameters

Model fit Table 2 summarizes the model's fit for a set of selected variables that describe the government's budget. The first row reports government spending as a percentage of GDP during ordinary times $\left(\mathrm{GS}_{o} / \mathrm{GDP}\right)$, while the second row includes both ordinary and extraordinary times (GS/GDP). The third row reports the ratio of government debt to GDP (Debt/GDP), while the fourth one reports government revenue as a proportion of GDP (GR/GDP). In the model, the

\footnotetext{
8 These tables are available online at: http://www.whitehouse.gov/omb/budget/Historicals. The series for the ratio of government spending to GDP consists of Total Outlays of the Federal Government, net of interest payments as a fraction of GDP. The Total Outlays measure includes Defense, Social Security and Veterans Compensation (so "mandatory" expenditures are taken into account when calibrating average spending). This measure is provided in Table 1.1 "Summary of receipts, outlays, and surpluses or deficits (-): 1789-2017". Interest payments are obtained from Table 3.1 "Outlays by superfunction and function: 1940-2017". GDP can be found in Table 10.1 "Gross domestic product and deflators used in the Historical Tables: 1940-2017". The debt series corresponds to Gross Federal Debt, in Table 7.1 "Federal debt at the end of year: 1940-2017".

${ }^{9}$ Using the theoretical distribution approach resulted in more robust estimates of the moments than the alternative of simulating the economy for a given length of time.

10 Our computational procedure is outlined in Appendix B.
} 
latter is simply the proportional income tax rate $\tau$. Average values observed in the data are displayed in the first column, while the second column reports the simulated model's counterpart. Standard deviations are summarized in the last two columns.

\begin{tabular}{l|rl|rr}
\hline \multirow{2}{*}{ Moment } & \multicolumn{2}{|c|}{ Mean } & \multicolumn{2}{c}{ St. Deviation } \\
& Data & Model & Data & Model \\
\hline \hline & & & & \\
GSn/GDP & $17.1 \%$ & $17.1 \% *$ & $2.6 \%$ & $2.6 \%$ \\
GS/GDP & $18.0 \%$ & $18.1 \%$ & $5.4 \%$ & $5.3 \%$ \\
Debt/GDP & $57.0 \%$ & $57.3 \% *$ & $21.0 \%$ & $17.0 \%$ \\
GR/GDP=tax & $16.8 \%$ & $21.1 \%$ & $2.3 \%$ & $1.0 \%$ \\
\hline
\end{tabular}

Notes: * indicates moments matched by construction.

Table 2: Model simulation vs. data

The mean and standard deviation of ordinary times spending as a ratio of GDP, as well as the mean debt/GDP ratio, are three of our five target values, and thus match the data well by construction. ${ }^{11}$ Note that the mean of spending/GDP (second column) predicted by the model matches the data well. Since this mean is a combination of the two conditional means (ordinary and extraordinary times), with the weights determined by the probability of extraordinary times, this suggests that our approximation of the shock process is accurate. Consistent with tax smoothing principles, we see from Table 2 that the volatility of the debt/GDP ratio in the data is much higher than that of the revenue/GDP ratio ( $21 \%$ for the former, $2.3 \%$ for the latter). Despite the fact that we did not directly target the debt/GDP volatility, the model generated a value quantitatively similar to that observed in the data. The predicted volatility of revenue/GDP is much lower than in the data suggesting that there is more tax smoothing going on in the model than in the actual economy. Moreover, the average revenue/GDP ratio generated by the model is a little higher than in the data. ${ }^{12}$

\footnotetext{
11 The other two target moments used in the calibration (mean $\mathrm{GS}_{e} / \mathrm{GDP}=40 \%$ and $\max$ Debt/GDP $=119 \%$ ) are matched exactly in the simulated data.

12 This may be because our specification of the discount factor $(\delta=0.95)$ implies that the annual interest rate on bonds $\rho$ is $5.26 \%$, as traditionally assumed in the literature. This is significantly higher than the average interest rate on Treasury bills over the period under study which is around $2 \%$. This implies that interest payments in the model are higher than in the data, and hence the government needs to tax more on average to satisfy its budget constraint. Of course, we could reduce the model's implied interest rate by lowering the discount factor, but then the value of $q$ implied by the calibration becomes implausibly high and the quality of the fit of the model as regards the debt distribution is compromised.
} 


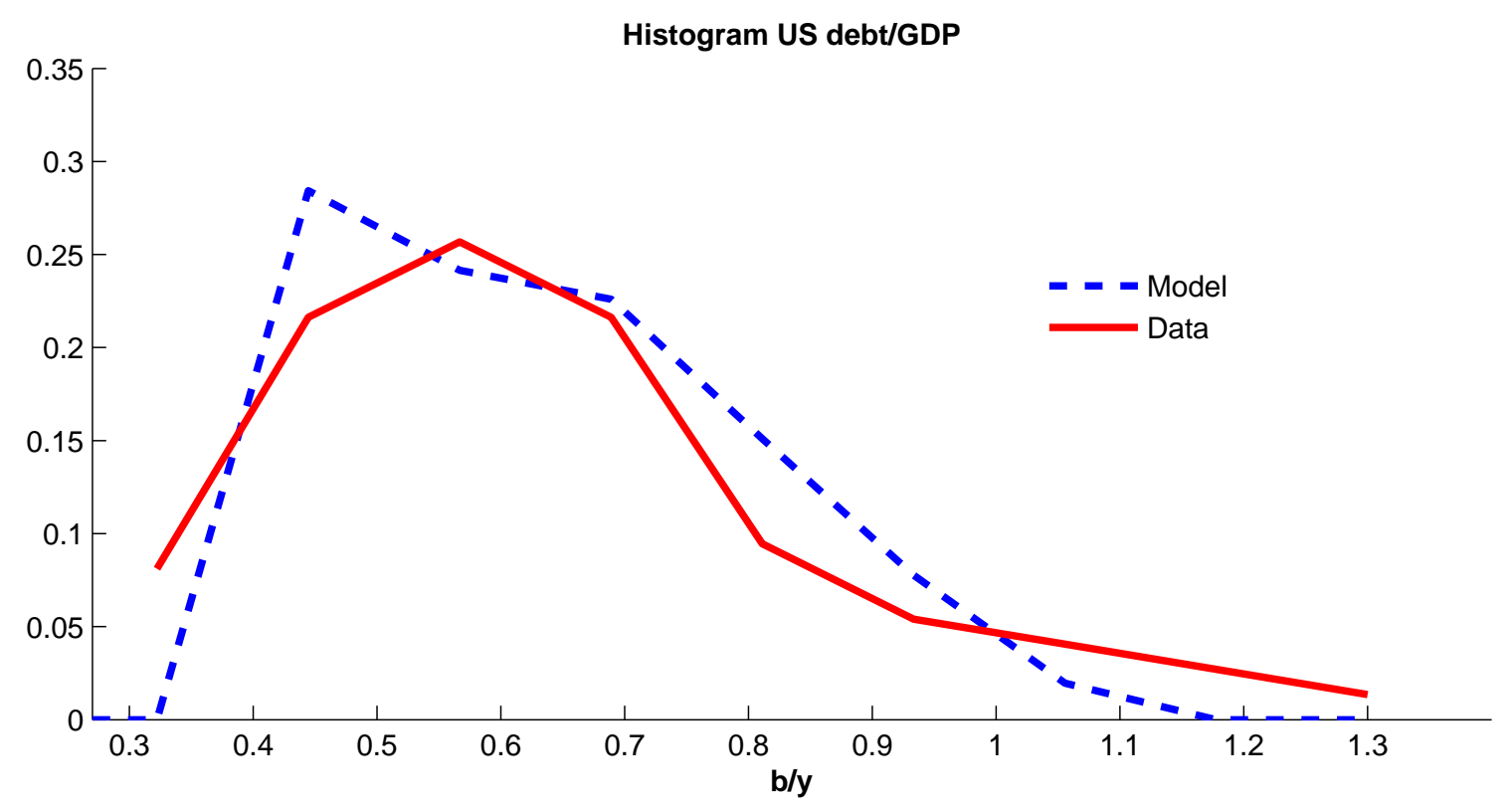

Figure 4: Stationary distribution of debt/GDP

There is one other statistic not reported in Table 2 that is nonetheless important to mention: the lower bound on the debt/GDP ratio. In the data, this was never below $29 \%$. The lower bound generated by the model is $30 \%$. Thus, the political frictions captured by the model generate quantitatively a realistic and endogenous lower bound for debt. Moreover, the long-run stationary distribution of debt/GDP that our model generates is in line with that observed in the U.S. as seen in Figure 4.

Discussion The quantitative version of the BC model provides a reasonably good fit of the data given its simplicity. In particular, the fit of the debt distribution illustrated in Figure 4 is impressive. Nonetheless, as a description of U.S. federal fiscal policy-making, the model has many limitations and an awareness of them is important in assessing the results from the policy experiment we undertake. We therefore briefly discuss what we see as three key limitations.

First, although dynamic, the BC model does not allow for persistent growth. Since there has been substantial growth in the U.S. economy over the period in question, to choose parameters it is necessary to match the predictions of the model concerning policies as a proportion of GDP with the data on policies as a proportion of GDP. Matching policy levels, even when corrected for 
inflation, would not be possible. But this raises the question of whether the equilibrium behavior of fiscal policies that the model predicts would emerge in a growing economy. For example, would the debt/GDP ratio in a growing economy behave the same as the debt/GDP ratio in the stationary economy? This is an open question. ${ }^{13}$

Second, the BC model does not incorporate entitlement spending. To fit the model to the data, we treat Social Security and Medicare spending as spending on the public good. However, it is clear that spending on these programs is driven by a different dynamic then spending on discretionary programs such as defense. ${ }^{14}$ Moreover, spending on these programs has grown significantly since World War II. When we choose our calibrated parameters, this growth is absorbed in our shock structure. Since this shock structure is assumed to be constant over the entire period in question, the model is not capturing the forces underlying this growth in entitlements spending.

Third, the BC model assumes a constant marginal utility of consumption. This assumption means that, given the interest rate $\rho$, citizens are indifferent over the time path of their consumption. This results in consumption being more volatile in the model than in the data. ${ }^{15}$ The assumption also implies that the interest rate is constant so that the model cannot capture the implications of fiscal policy changes for interest rates. ${ }^{16}$

\subsection{Impact of a strict BBR}

Table 3 compares fiscal policy variables in the invariant distribution under a BBR with those in the unconstrained case. The most striking difference is in the debt/GDP ratio which is reduced from $57.3 \%$ to $3.3 \%$ - a $94 \%$ decline. The steady state average revenue/GDP ratio is lower with a BBR and the mean spending/GDP ratio in ordinary times is higher. However, the variance of

\footnotetext{
13 Barshegyan and Battaglini (2014) develop a growth model which shares some features of the BC model. In their model, growth is driven by learning-by-doing and public investment. In common with the BC model, policy decisions are made by a legislature and legislators are able to target resources to their districts which leads to excessive debt. The authors study the impact of an austerity program which forces a reduction in the debt/GDP ratio to a target level over a given number of periods. However, the role of debt in their model differs from that in the $\mathrm{BC}$ model because there are no shocks and hence no role for tax smoothing.

${ }^{14}$ In particular, a key feature of such spending is that it is not determined period by period as the spending is in the BC model. Rather increases in program benefits in the current period will have implications for spending in subsequent periods. Following Bowen, Chen and Eraslan (2014), one might try to model this by assuming that the current period's spending on such programs determines next period's status quo spending level on such programs.

15 The standard deviation of consumption as a proportion of GDP is $5.4 \%$ in the model and $3.8 \%$ in the data.

16 In addition, with a diminishing marginal utility of consumption, the government will have incentives to manipulate the interest rate in its favor. Given a lack of commitment, this would cause further distortions in a political equilibrium. For a discussion of this, see Lucas and Stokey (1983) for the benevolent planner case and Azzimonti, deFrancisco and Krusell (2008) and Barshegyan and Battaglini (2014) for alternative political economy scenarios.
} 
the spending/GDP ratio is lower with a BBR reflecting the fact that public good provision is less responsive to preference shocks. The variance of tax rates is higher with a BBR, reflecting the intuition that taxes should be less smooth. In the unconstrained case, the economy can have both responsive public good provision and smooth taxes by varying debt. This is evidenced by the high variance of the debt/GDP ratio without a BBR. The Table also shows that the mean level of pork as a fraction of government spending is much higher in the steady state under a BBR than in the long run in the unconstrained case. Notice that in both cases pork is a very small fraction of government spending, so that the difference in spending/GDP ratios across the two regimes translates into a difference in public good spending/GDP ratios.

\begin{tabular}{|c|c|c|c|c|}
\hline \multirow{2}{*}{ Moment } & \multicolumn{2}{|l|}{ Mean } & \multicolumn{2}{|c|}{ St. Deviation } \\
\hline & Benchmark & $B B R$ & Benchmark & $B B R$ \\
\hline GSo/GDP & $17.1 \%$ & $18.7 \%$ & $2.6 \%$ & $2.6 \%$ \\
\hline GS/GDP & $18.1 \%$ & $18.3 \%$ & $5.3 \%$ & $3.4 \%$ \\
\hline Debt/GDP & $57.3 \%$ & $3.3 \%$ & $17.0 \%$ & $0.2 \%$ \\
\hline $\mathrm{GR} / \mathrm{GDP}=\tau$ & $21.1 \%$ & $19.4 \%$ & $1.0 \%$ & $2.0 \%$ \\
\hline Pork/GS & $0.02 \%$ & $2.76 \%$ & $0.32 \%$ & $5.6 \%$ \\
\hline
\end{tabular}

Table 3: Long run effects of a BBR

Transitional dynamics To understand the dynamic impact of imposing a BBR, we simulated the economy by drawing a sequence of shocks consistent with our assumed distribution of $A$. As an initial condition, we assumed that the debt/GDP ratio equalled $96 \%$, the level prevailing in 2013. It took around 70 periods for the economy to transition to a debt level close to $b^{*}$ (the equivalent of about a $30 \%$ debt/GDP ratio), with the convergence to the new steady state (about a $3 \%$ debt/GDP ratio) occurring at a much slower speed.

Figure 5 compares the dynamics of fiscal policy with and without a BBR. As can be seen in the first panel, in the unconstrained case (the red dotted line) the government always issues debt in extraordinary times: with a BBR, however, it is forced to have zero deficits. This induces a marked downward drift in the evolution of debt. The second panel measures the debt/GDP ratio. Note that this measure spikes during extraordinary times even with a BBR. The reason is that, even though debt remains constant, GDP goes down due to the increase in taxation needed to finance the large negative shock (e.g., war). The spike in taxes during extraordinary times under a BBR is clearly illustrated in the third panel which nicely illustrates the negative consequences 

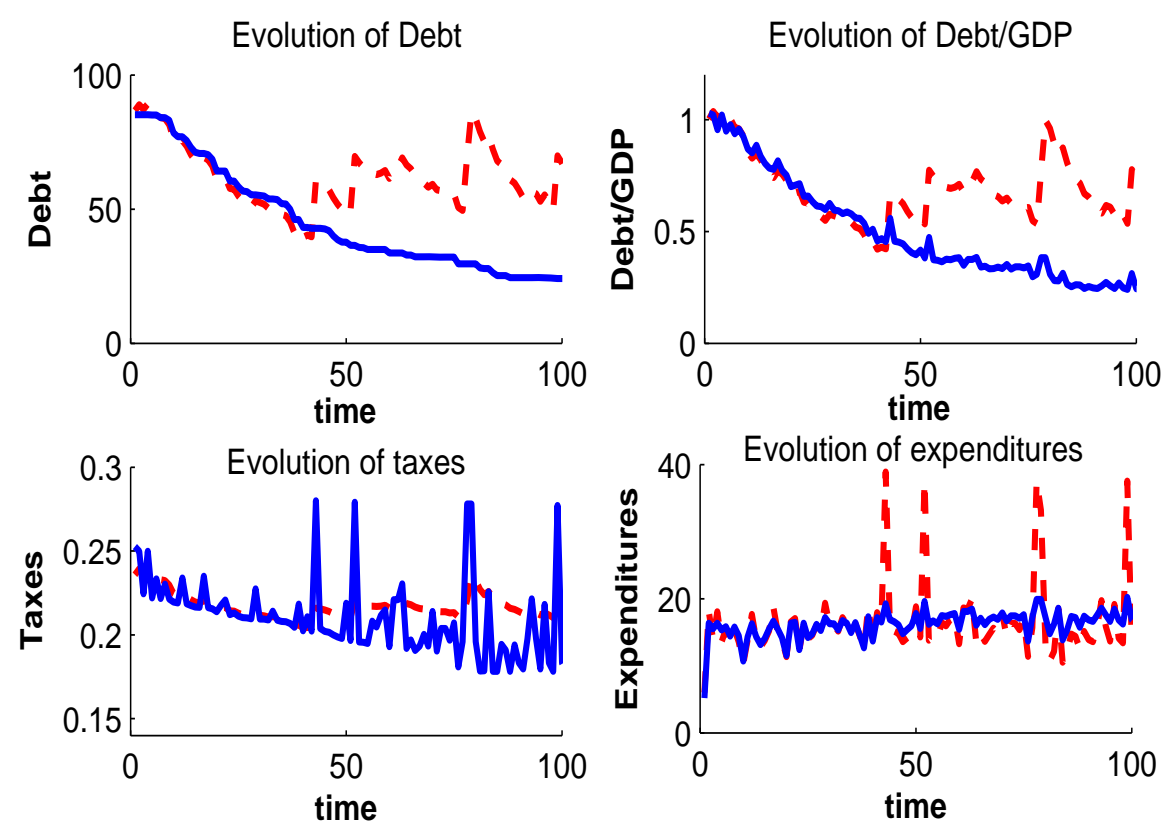

Figure 5: Evolution of key variables (- - red benchmark, - blue BBR )

of a BBR for tax smoothing. On the other hand, the panel also illustrates how a BBR serves to lower average tax rates over time. The fourth and final panel of Figure 5 illustrates that public good provision is much less responsive with a BBR. However, the average level of public good provision rises above the level of provision without a BBR as debt converges to the new steady state.

Figure 6 looks at the evolution of pork and debt with a BBR under the same sequence of shocks as that associated with Figure 5. Pork is not provided when the BBR is initially imposed but is provided with increasing frequency as debt levels decline. This reflects the fact that the lower costs of servicing debt allows the mwc to be more generous to their districts.

Welfare Steady state welfare under a strict BBR, as measured by $E v_{c}\left(b_{0}, A\right)$, is $3.14 \%$ higher than the corresponding long run value in the unconstrained case. ${ }^{17}$ This welfare gain reflects the lower cost of debt service at the new steady state. However, as discussed above, the fact that steady state welfare is higher does not mean that imposing a BBR will raise welfare because of the costs incurred in the transition to the new steady state. Figure 7 illustrates the evolution of

\footnotetext{
${ }^{17}$ Long run welfare without a $\mathrm{BBR}$ is given by $\int_{b} E v(b, A) d \psi(b)$ where $\psi(b)$ is the invariant distribution of debt.
} 


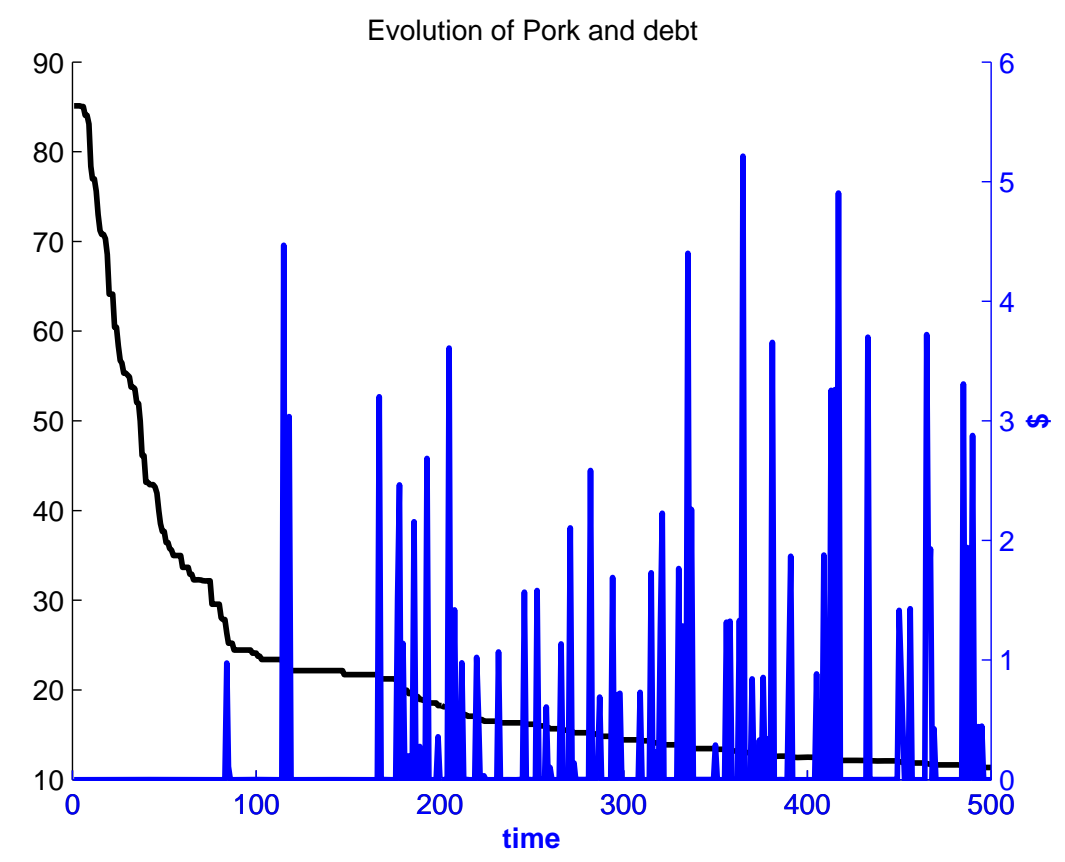

Figure 6: Evolution of pork and debt under a BBR

contemporaneous utility following the imposition of a BBR as a percentage of the contemporaneous utility realized in the unconstrained case. After 40 periods, debt is sufficiently lower under a BBR that contemporaneous utility typically overtakes that in the unconstrained equilibrium except during extraordinary times. Nonetheless, the short run costs are sufficiently high that imposing a BBR given the level of debt in the U.S. in 2013 will actually reduce welfare. Moreover, this is true for any initial debt level in the support of the long run distribution in the unconstrained equilibrium.

While the question is more academic, one can also use the quantitative version of the model to ask whether citizens in the economy would have been better off at its founding banning deficits (i.e., if a strict BBR were imposed at time 0 before the government had accumulated any debt). Assuming that initial debt equals zero and that $b_{0}$ (as defined in (18)) exceeds 0 , under such a BBR, debt would remain at 0 forever. Thus, we can quantify the welfare gains of introducing a BBR at foundation by comparing $E v_{c}(0, A)$ and $E v(0, A)$ in the quantitative model. ${ }^{18}$ We find that such a ban would have increased welfare by $0.05 \%$.

\footnotetext{
18 This comparison is the one analyzed in Battaglini and Coate (2008). They prove that if $R\left(\tau^{*}\right)$ exceeds $p g^{*}(\bar{A})$, then it must be the case that $\operatorname{Ev} v_{c}(0, A)$ exceeds $\operatorname{Ev}(0, A)$ and a BBR is welfare improving. To see the logic, note that the condition implies that $A^{*}(0,0)$ exceeds $\bar{A}$ and hence the tax-public good pair would always be $\left(\tau^{*}, g^{*}(A)\right)$ under a BBR. But without a BBR, by Proposition 2, the tax rate would never be lower than $\tau^{*}$ and sometimes would be strictly higher and the public good level would never be higher than $g^{*}(A)$ and sometimes would be strictly lower. Thus, citizens must be better off with a BBR. This condition, however, is quite restrictive and is not satisfied in the quantitative version of the model.
} 


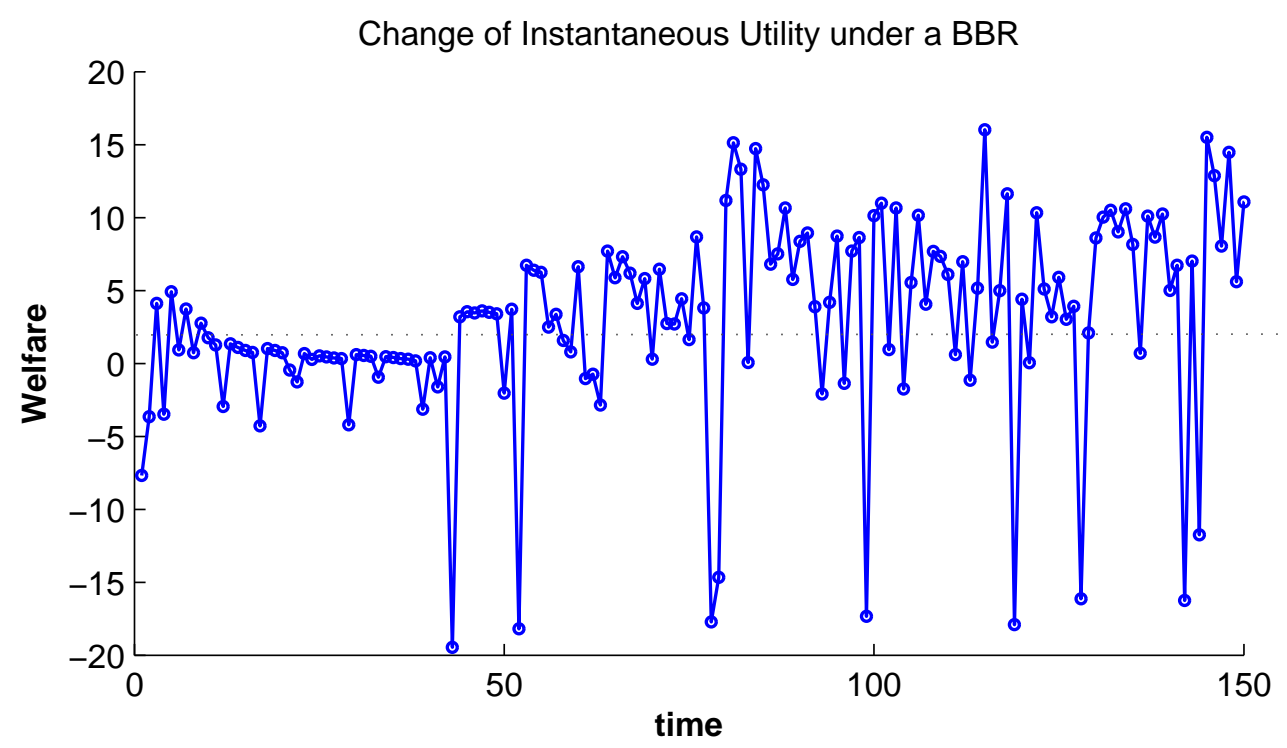

Figure 7: The evolution of welfare

\section{Impact of a BBR with super-majority override}

Now consider the impact of a BBR that can be overruled with the support of $q^{\prime}>q$ legislators. Thus, if the proposer can obtain the support of $q^{\prime}$ legislators, he can pass a proposal which runs a deficit and raises the debt level. Otherwise, the rule binds. Of course, if the proposer is not planning to raise debt, then he only needs the support of $q$ legislators to pass his proposal. We now have the following striking result.

Proposition 7. Suppose that a BBR with super-majority override is imposed on the economy when the debt level is at least $b^{*}$. Then the rule will have no effect on fiscal policies and citizens' welfare.

The logic underlying this result is straightforward. In the long run equilibrium of the unconstrained model, a mwc never simultaneously runs a deficit and provides pork. This follows from the fact that when a mwc provides pork it chooses the debt level $b^{*}$ which is the lowest level of debt in the support of the long run distribution. Thus, whenever the mwc runs a deficit it is effectively behaving as a planner would and its proposal is therefore supported unanimously. Requiring the mwc to obtain additional support for its deficit-financed proposal therefore imposes no constraint on its behavior. 
When reflecting on this result, it is important to note that if a BBR with override were imposed on the economy before debt had risen to equilibrium levels, it would have an effect. This is because it will constrain the initial surge in deficit-financed pork which increases debt to $b^{*}$ and will therefore shift the debt distribution to the left. The greater the required super-majority, the larger the shift. This leftward shift in the debt distribution would likely enhance social welfare.

\section{Discussion}

The BC model offers a clear account of the social costs and benefits of imposing a strict BBR. The social cost is less responsive public good provision and greater volatility in tax rates. The inability to run deficits means that the only way to respond to positive shocks in the value of the public good is to raise taxes. This leads to sharper tax hikes. Moreover, since the marginal cost of public funds is higher, public good provision incentives are dampened. The social benefit of a strict $\mathrm{BBR}$ is that the level of debt is reduced. While this reduction imposes short run costs, in the long run citizens benefit since debt starts out inefficiently high. The lower debt burden permits higher average levels of public goods and lower taxes.

This account of the social cost of a strict BBR is consistent with the policy debate. ${ }^{19}$ The major drawback of a balanced budget amendment to the U.S. constitution stressed by opponents is that it reduces the federal government's ability to deal with emergency spending needs and/or unexpected revenue shortages. Emergency spending needs include wars, natural disasters, and the need to pump-prime the economy in recessions. ${ }^{20}$ Revenue shortages come from business cycle fluctuations. The inability of the government to run deficits in these circumstances is predicted to lead to inadequate federal spending and/or excessive taxation. ${ }^{21}$

The account of the social benefit of a strict BBR is also consonant with the policy debate.

\footnotetext{
${ }^{19}$ For a useful introduction to the policy debate concerning a balanced budget amendment to the U.S. constitution see Sabato (2007) pp. 54-69. While many economists have come out against a balanced budget amendment (as documented in Levinson (1998)), economists who have advocated for such an amendment include Nobel Laureates James Buchanan and Milton Friedman, and former chairman of President Reagan's Council of Economic Advisors William Niskanen.

20 Typically, however, the amendments considered by the U.S. Congress specify that the BBR is to be automatically waived in times of war.

${ }^{21}$ Inadequate spending tends to be emphasized because the view is that political opposition to tax hikes will be higher than to spending cut-backs. This reflects the fact that federal spending programs are often targeted to particular sub-groups of the population, while taxes are paid by a broader group of citizens. In the BC model, all citizens are homogeneous in their preferences over public good provision and taxes and therefore these are always kept in balance.
} 
Advocates of a balanced budget amendment certainly see the main goal as being to reduce the debt burden on the economy. A key lesson of the BC model is that it spells out an explicit mechanism by which debt reduction occurs. The model is also useful in clarifying what happens to government taxes and spending. Many advocates seem to assume that BBRs will lead to smaller government. If the size of government is measured by the tax rate, then the quantitative version of the model suggests that on average this is true (see Table 3). Nonetheless, average spending on both public goods and pork will in fact increase. This suggests that if the true goal of a BBR is to reduce government spending, it should be supplemented by tax or spending limits.

The force leading to debt reduction in the $\mathrm{BC}$ model is that a BBR, by restricting future policies, increases the expected cost of taxation and increases legislators' incentive to save. It is worth noting that, in a growing economy, there will be an additional, purely mechanical, force driving down the debt/GDP ratio. A strict BBR, by banning deficits, amounts to a constraint that the current level of debt cannot exceed the initial level. ${ }^{22}$ Accordingly, if GDP is growing, the debt/GDP ratio must fall even if debt is constant. Exactly how this force will combine with the force identified by our analysis is an open question, but the direction of the overall effect is unambiguous.

Our quantitative assessment of the relative size of the social costs and benefits is, of course, highly model dependent. It is interesting to give a sense of the strength of the forces at work, but as we noted earlier, the model has its limitations. It is easy to think of factors that could substantially increase both the costs and the benefits of a BBR. On the cost side, if Keynesian pump-priming could prevent recessions from deepening, then cramping the federal government's ability to engage in it might indeed be very costly. On the benefit side, if reducing government debt would decrease interest rates and spur private investment and growth, then the benefits of government debt reduction could be much greater than suggested by the model. ${ }^{23}$

Imposing a BBR with super-majority override will have no effect according to the BC model. This conclusion reflects the fact that once debt is at equilibrium levels, deficits are used to finance

\footnotetext{
22 This is as opposed to a constraint that today's debt/GDP ratio cannot exceed tomorrow's. In some sense, a constraint that the debt/GDP ratio cannot grow seems a more natural rule to propose for a growing economy than a BBR (as argued by Paget (1996)). Indeed, rules that cap the debt/GDP ratio below some level are common in countries outside the U.S. (see Corsetti and Roubini (1996)).

23 That said, these considerations would impact the equilibrium level of debt in the unconstrained case so that the change created by the BBR might be much less dramatic. Of course, this is why an equilibrium analysis such as ours is necessary to predict the impact of imposing a BBR.
} 
only public good spending and not targeted pork. They are therefore supported unanimously. Thus, while the equilibrium level of debt is excessive, deficits are, in a sense, not excessive in long run equilibrium. We suspect that this feature reflects the stationary nature of the underlying economy and would not be robust to including growth. In a growing economy, the debt level will likely grow over time even when the mwc is providing pork. Thus, rather than being an absolute level of debt, $b^{*}$ would be the debt/GDP ratio that is chosen when the mwc provides pork. If GDP is increasing, then in order to maintain the debt/GDP ratio at $b^{*}$, the mwc will have to issue new debt and thereby run a deficit. But if the mwc needs super-majority approval to run a deficit, then it may be constrained in its ability to do so. Accordingly, we expect a BBR with override might have an effect. Of course, exactly what this effect will be is an open question.

Given the possible non-robustness of the ineffectiveness result to introducing growth, we must be cautious in treating it as a definitive prediction. Nonetheless, we do feel that the result is useful in focusing attention on the question of exactly how a BBR is supposed to make a difference when it can be overridden by a super-majority of legislators. Advocates of a balanced budget amendment to the U.S. constitution usually support an override to preserve some flexibility, but implicitly assume that a requirement to get the support of, say, 3/5ths of both Houses of Congress will have bite. Indeed, the discussion tends to focus on the concern that such a requirement might be too stringent and could lead to hold up problems with legislators demanding special projects for their districts in exchange for their votes. The theoretical and/or empirical justification for these views is obscure and the ineffectiveness result poses an interesting challenge to them.

\section{Conclusion}

This paper has studied the impact of a BBR in the political economy model of fiscal policy developed by Battaglini and Coate (2008). The paper has analyzed, both qualitatively and quantitatively, the impact of imposing two different types of BBRs: a strict rule that cannot be circumvented by the legislature and a rule that can be overridden by a super-majority of legislators. We feel that the analysis offers some interesting lessons concerning the likely impact of a strict BBR. The key theoretical insight is that imposing a strict BBR will lead legislators to reduce existing debt levels. By restricting future policies, a BBR increases the expected cost of taxation and makes public savings more valuable. This reduction in debt has beneficial long run effects because it reduces the revenues that must be devoted to servicing the debt. These beneficial effects must 
be weighed against the costs of less responsive public good provision and more volatile tax rates. While we are less satisfied with the prediction of the model concerning the (non) impact of a BBR with a super-majority override, we do feel that it is useful in raising the question of exactly how such a BBR is supposed to make a difference. This is an important question which the policy debate has paid insufficient attention to.

In terms of future research, we belive there is much scope for further analysis of the impact of BBRs in political economy models of fiscal policy. It would be particularly interesting to study the issue in models that incorporated growth. We suspect that different conclusions concerning the impact of a BBR with super-majority override would emerge. Political economy models that incorporate unemployment and a Keynesian role for fiscal policy would also present an interesting laboratory for study of the issue. More generally, the analysis of alternative types of fiscal restraints would be very interesting. Such alternatives include rules that limit a country's debt/GDP ratio or require that budget deficits are less than a certain fraction of GDP. It is important to understand which rules work best. ${ }^{24}$ Trying to resolve such policy questions is a natural focus for political economy models of fiscal policy.

\footnotetext{
24 The importance of this agenda is reflected in a number of interesting recent papers. Halac and Yared (2014) adopt a dynamic mechanism design approach to the choice of fiscal rules in a simple political economy model of fiscal policy. Martin (2015) provides an evaluation of a variety of different monetary and fiscal constraints in the framework of Lagos and Wright (2005). Hatchondo, Martinez and Roch (2012) study optimal fiscal rules in a model of sovereign default.
} 


\section{References}

Alt, J. and R. Lowry, (1994), "Divided Government and Budget Deficits: Evidence from the States," American Political Science Review, 88(4), 811-828.

Azzimonti, M., E. deFrancisco and P. Krusell, (2008), "Production Subsidies and Redistribution," Journal of Economic Theory, 142(1), 73-99.

Barro, R., (1979), "On the Determination of the Public Debt," Journal of Political Economy, 87, 940-971.

Barshegyan, L. and M. Battaglini, (2014), "Political Economy of Debt and Growth," mimeo, Cornell University.

Barshegyan, L., M. Battaglini and S. Coate, (2013), "Fiscal Policy over the Real Business Cycle: A Positive Theory," Journal of Economic Theory, 148(6), 2223-2265.

Battaglini, M. and S. Coate, (2008), "A Dynamic Theory of Public Spending, Taxation and Debt," American Economic Review, 98(1), 201-236.

Bayoumi, T. and B. Eichengreen, (1995), "Restraining Yourself: The Implications of Fiscal Rules for Economic Stabilization," IMF Staff Papers, 42, 32-48.

Besley, T. and M. Smart, (2007), "Fiscal Restraints and Voter Welfare," Journal of Public Economics, 91, 755-773.

Bohn, H. and R. Inman, (1996), "Balanced Budget Rules and Public Deficits: Evidence from the U.S. States," Carnegie-Rochester Conference Series on Public Policy, 45, 13-76.

Bowen, R., Y. Chen and H. Eraslan, (2014), "Mandatory vs Discretionary Spending: The Status Quo Effect," American Economic Review, 104(10), 2941-2974.

Braun, M., (1992), Differential Equations and their Applications, 4th Edition, New York: Springer-Verlag.

Brennan, G. and J. Buchanan, (1980), The Power to Tax: Analytical Foundations of a Fiscal Constitution, Cambridge: Cambridge University Press.

Buchanan, J., (1995), "Clarifying Confusion about the Balanced Budget Amendment," National Tax Journal, 48, 347-355.

Buchanan, J. and R. Wagner, (1977), Democracy in Deficit: The Political Legacy of Lord Keynes, New York: Academic Press.

Chari, V.V., L. Christiano and P. Kehoe, (1994), "Optimal Fiscal Policy in a Business Cycle Model," Journal of Political Economy, 102(4), 617-652.

Cooley, T. and E. Prescott, (1995), "Economic Growth and Business Cycles," in Cooley, T. ed, Frontiers of Business Cycle Research, Princeton: Princeton University Press.

Corsetti, G. and N. Roubini, (1996) "European and American Perspectives on BalancedBudget Rules," American Economic Review, 86(2), 408-413.

Fatas, A. and I. Mihov, (2006), "The Macroeconomic Effects of Fiscal Rules in the U.S. States," Journal of Public Economics, 90, 101-117. 
Greenwood, J., Z. Hercowitz and G. Huffman, (1988), "Investment, Capacity Utilization, and the Real Business Cycle," American Economic Review, 78, 402-417.

Halac, M. and P. Yared, (2014), "Fiscal Rules and Discretion under Persistent Shocks," Econometrica, 82(5), 1557-1614.

Hatchondo, J., L. Martinez and F. Roch, (2012), "Fiscal Rules and the Sovereign Default Premium," Federal Reserve Bank of Richmond Working Paper \#12-01.

Hou, Y. and D. Smith, (2006), "A Framework for Understanding State Balanced Budget Requirement Systems: Reexamining Distinctive Features and an Operational Definition," Public Budgeting and Finance, 26(3), 22-45.

Hou, Y. and D. Smith, (2010), "Do State Balanced Budget Requirements Matter? Testing Two Explanatory Frameworks," Public Choice, 145, 57-79.

Inman, R., (1996), "Do Balanced Budget Rules Work? U.S. Experience and Possible Lessons for the EMU," NBER Working Paper \#5838.

Keech, W., (1985) "A Theoretical Analysis of the Case for a Balanced Budget Amendment," Policy Sciences, 18, 157-168.

Lagos, R. and R. Wright, (2005), "A Unified Framework for Monetary Theory and Policy Analysis," Journal of Political Economy, 113(3), 463-484.

Levinson, A., (1998), "Balanced Budgets and Business Cycles: Evidence from the States," National Tax Journal, 51(4), 715-732.

Lucas, R. and N. Stokey, (1983), "Optimal Fiscal and Monetary Policy in an Economy without Capital," Journal of Monetary Economics, 12, 55-93.

Martin, F., (2015), "The Value of Constraints on Discretionary Government Policy," mimeo, Federal Reserve Bank of St Louis.

Niskanen, W., (1992), "The Case for a New Fiscal Constitution," Journal of Economic Perspectives, 6(2), 13-24.

Paget, K., (1996), "The Balanced Budget Trap," The American Prospect, 29, 21-29.

Poterba, J., (1994), "State Responses to Fiscal Crises: The Effects of Budgetary Institutions and Politics," Journal of Political Economy, 102, 799-821.

Poterba, J., (1995), "Balanced Budget Rules and Fiscal Policy: Evidence from the States," National Tax Journal, 48(3), 329-336.

Poterba, J., (1996), "Budget Institutions and Fiscal Policy in the U.S. States," American Economic Review, 86(2), 395-400.

Rose, S., (2006), "Do Fiscal Rules Dampen the Political Business Cycle?" Public Choice, $128,407-431$.

Rose, S., (2010), "Institutions and Fiscal Sustainability," National Tax Journal, 63(4), 807838 .

Sabato, L., (2007), A More Perfect Constitution, New York: Walker Publishing Company. 
Savage, J., (1988), Balanced Budgets and American Politics, Ithaca: Cornell University Press.

Stockman, D., (2001), "Balanced-Budget Rules: Welfare Loss and Optimal Policies," Review of Economic Dynamics, 4, 438-459.

von Hagen, J., (1991), "A Note on the Empirical Effectiveness of Formal Fiscal Restraints," Journal of Public Economics, 44(2), 199-210.

von Hagen, J., (2002), "Fiscal Rules, Fiscal Institutions, and Fiscal Performance," Economic and Social Review, 33(3), 263-284.

Whalen, C., (1995), "The Balanced Budget Amendment: Toxic, not Tonic," mimeo, The Jerome Levy Economics Institute of Bard College. 


\section{Appendix A}

\subsection{Proof of Proposition 4}

We begin by characterizing what the function $b_{c}^{*}(b)$ must look like in a well-behaved equilibrium. Using Proposition 3, we can write the equilibrium value function as:

$$
\begin{aligned}
& v_{c}(b, A)=\left\{\begin{array}{c}
\max _{(\tau, g)}\left\{\begin{array}{c}
u(\tau)+A \ln g+\frac{B(\tau, g, b, b)}{n}+\delta E v_{c}\left(b, A^{\prime}\right) \\
: B(\tau, g, b, b) \geq 0
\end{array}\right\} \quad \text { if } A>\widehat{A}(b) \\
\max _{\left(\tau, g, b^{\prime}\right)}\left\{\begin{array}{c}
u(\tau)+A \ln g+\frac{B\left(\tau, g, b^{\prime}, b\right)}{n}+\delta E v_{c}\left(b^{\prime}, A^{\prime}\right) \\
: B\left(\tau, g, b^{\prime}, b\right) \geq 0
\end{array}\right\} \quad \text { if } A \in\left[A^{*}\left(b, b_{c}^{*}(b)\right), \widehat{A}(b)\right]
\end{array}\right. \\
& u\left(\tau^{*}\right)+A \ln \frac{q A}{p}+\frac{B\left(\tau^{*}, \frac{q A}{p}, b_{c}^{*}(b), b\right)}{n}+\delta E v_{c}\left(b_{c}^{*}(b), A^{\prime}\right) \quad \text { if } A<A^{*}\left(b, b_{c}^{*}(b)\right),
\end{aligned}
$$

where $\widehat{A}(b)$ is the threshold (possibly larger than $\bar{A}$ ) such that for $A \geq \widehat{A}(b)$ the BBR constraint that the debt level be less than $b$ will bind. In this top range, the initial debt level will directly determine the debt level chosen next period. Using this and the assumption that the equilibrium is well-behaved, we have that

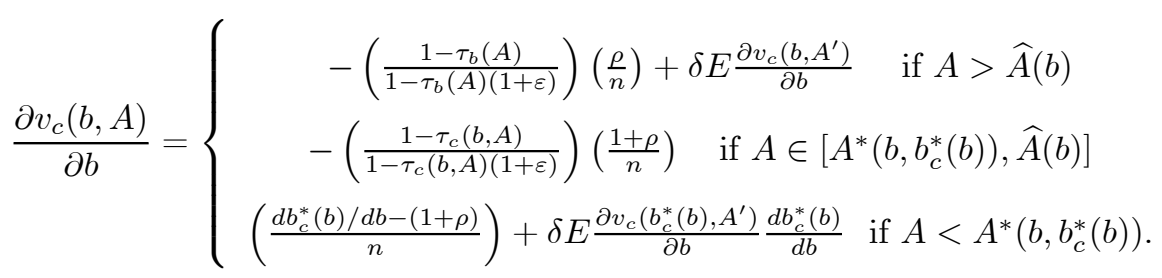

Taking expectations, we obtain

$$
\begin{gathered}
-\delta n E \frac{\partial v_{c}(b, A)}{\partial b}=G\left(A^{*}\left(b, b_{c}^{*}(b)\right)\right) \delta\left[1+\rho-\frac{d b_{c}^{*}(b)}{d b}-n \delta E \frac{\partial v_{c}\left(b_{c}^{*}(b), A\right)}{\partial b} \frac{d b_{c}^{*}(b)}{d b}\right] \\
+\int_{A^{*}\left(b, b_{c}^{*}\right)}^{\min \{\bar{A}(\widehat{l})\}}\left(\frac{1-\tau_{c}(b, A)}{1-\tau_{c}(b, A)(1+\varepsilon)}\right) d G(A) \\
+\int_{\min \{\bar{A}, \widehat{A}(b)\}}^{\bar{A}}\left(\frac{1-\tau_{b}(A)}{1-\tau_{b}(A)(1+\varepsilon)}\right) d G(A)(1-\delta)-\delta^{2} n E \frac{\partial v_{c}(b, A)}{\partial b}(1-G(\min \{\bar{A}, \widehat{A}(b)\})) .
\end{gathered}
$$

Now let $b_{0}$ and $b_{1}$ be as defined in (14) and (15). As explained in the text, we must have that $b_{0}$ is less than $b_{1}$. We now characterize the end point $b_{0}$. When $b<b_{0}$, we know that $b_{c}^{*}(b)=b$ and hence that $\frac{d b_{c}^{*}(b)}{d b}=1$. Moreover, since $b_{c}^{*}(b)=b$, we have that $\widehat{A}(b)=A^{*}(b, b)$ and so we can rewrite (23) as:

$$
-\delta n E \frac{\partial v_{c}(b, A)}{\partial b}=G\left(A^{*}(b, b)\right)+\int_{A^{*}(b, b)}^{\bar{A}}\left(\frac{1-\tau_{b}(A)}{1-\tau_{b}(A)(1+\varepsilon)}\right) d G(A) .
$$


Since $\frac{b^{\prime}}{q}+\delta E v_{c}\left(b^{\prime}, A^{\prime}\right)$ is constant on the interval $\left[b_{0}, b_{1}\right]$, the right hand derivative of the value function at $b_{0}$ and the left hand derivative at $b_{1}$ must be $1 / q$. Since the expected value function is differentiable, then, we must have that at $b_{0}$ the left hand side derivative (which is given by (24)) is $1 / q$ implying that

$$
G\left(A^{*}\left(b_{0}, b_{0}\right)\right)+\int_{A^{*}\left(b_{0}, b_{0}\right)}^{\bar{A}}\left(\frac{1-\tau_{b_{0}}(A)}{1-\tau_{b_{0}}(A)(1+\varepsilon)}\right) d G(A)=\frac{n}{q} .
$$

This is (18).

The next step is to characterize $b_{c}^{*}(b)$ on the interval $\left[b_{0}, b_{1}\right]$. If $\frac{b}{q}+\delta E v_{c}\left(b, A^{\prime}\right)$ is constant on the interval $\left[b_{0}, b_{1}\right]$ we must have that

$$
-\delta n E \frac{\partial v_{c}(b, A)}{\partial b}=\frac{n}{q}
$$

for any $b \in\left[b_{0}, b_{1}\right]$. Since $E \frac{\partial v_{c}(b, A)}{\partial b}$ is a function of $b_{c}^{*}(b)$ and its derivative, (25) implies a differential equation that needs to be satisfied by $b_{c}^{*}(b)$ along with the initial condition $b_{c}^{*}\left(b_{0}\right)=b_{0}$. Using (23), we can show that this condition requires that $b_{c}^{*}(b)$ in $\left[b_{0}, b_{1}\right]$ is equal to a function $f(b)$ that solves the differential equation:

$$
\begin{gathered}
\frac{n}{q}=G\left(A^{*}(b, f(b))\right)\left[1-\frac{d f(b)}{d b} \delta\left(1-\frac{n}{q}\right)\right] \\
+\left(\frac{n}{q}\right)(1-\delta) G\left(A^{*}(b, b)\right)-\left(\frac{n}{q}\right) G\left(A^{*}(b, f(b))\right)+\int_{A^{*}(b, b)}^{\bar{A}}\left(\frac{1-\tau_{b}(A)}{1-\tau_{b}(A)(1+\varepsilon)}\right) d G(A)(1-\delta)+\delta \frac{n}{q},
\end{gathered}
$$

with the initial condition $f\left(b_{0}\right)=b_{0}$. This is (19). Note that if this condition is satisfied, then any point in $\left[b_{0}, b\right]$ would be a legitimate choice for $b_{c}^{*}(b)$ when $b \in\left[b_{0}, b_{1}\right]$. We are therefore free to choose $b_{c}^{*}(b)$ as we like - in particular, $b_{c}^{*}(b)=f(b)$. By Theorem $2^{\prime}$ in Braun (1992) (p.77), $f(b)$ is uniquely defined on $\left[b_{0}, \bar{b}\right]$.

The final step is to pin down the end point of the interval $b_{1}$. Because $b_{c}^{*}(b)$ is non decreasing and bounded in $\left[b_{0}, b_{1}\right]$, it must be constant and equal to $f\left(b_{1}\right)$ for debt levels $b$ larger than $b_{1}$. Using (23) and the fact that $\frac{d b_{c}^{*}(b)}{d b}=0$ for $b$ greater than $b_{1}$ we have that:

$$
\begin{gathered}
G\left(A^{*}\left(b, b_{c}^{*}(b)\right)\right)+\int_{A^{*}\left(b, b_{c}^{*}(b)\right)}^{\min \{\bar{A}, \widehat{A}(b)\}}\left(\frac{1-\tau_{c}(b, A)}{1-\tau_{c}(b, A)(1+\varepsilon)}\right) d G(A) \\
-\delta n E \frac{\partial v_{c}(b, A)}{\partial b}=\frac{+\int_{\min \{\bar{A}, \widehat{A}(b)\}}^{\bar{A}}\left(\frac{1-\tau_{b}(A)}{1-\tau_{b}(A)(1+\varepsilon)}\right) d G(A)(1-\delta)}{1-\delta(1-G(\min \{\bar{A}, \widehat{A}(b)\}))} .
\end{gathered}
$$

for $b$ greater than $b_{1}$. The same logic used to pin down $b_{0}$ can now be used for $b_{1}$ : at $b_{1}$ we need the right hand side derivative (given by (26)) equal to $1 / q$. This implies that $b_{1}$ must satisfy:

$$
\frac{n}{q}(1-\delta)=\frac{n}{q}(1-\delta) G\left(A^{*}\left(b_{1}, b_{1}\right)\right)-\left(\frac{n}{q}-1\right) G\left(A^{*}\left(b_{1}, f\left(b_{1}\right)\right)\right)+\int_{A^{*}\left(b_{1}, b_{1}\right)}^{\bar{A}}\left(\frac{1-\tau_{b_{1}}(A)}{1-\tau_{b_{1}}(A)(1+\varepsilon)}\right) d G(A)(1-\delta) .
$$


This is (20).

We now have a full characterization of the $b_{c}^{*}(b)$ function in a well-behaved equilibrium. Notice that for a given $b_{c}^{*}(b)$ function, (13) is a contraction with a unique fixed-point. Thus, since $b_{c}^{*}(b)$ is uniquely defined, there exists a unique well-behaved equilibrium.

\subsection{Proof of Proposition 5}

Note first from (13) and (17) that $b_{c}^{\prime}\left(b_{0}, A\right)=b_{0}$ for all $A$ so that $b_{0}$ is a steady state. The key step is therefore to show that the equilibrium level of debt must converge down to the level $b_{0}$. Let $\widehat{b} \in\left[b^{*}, \bar{b}\right)$ denote the debt level that is prevailing when the BBR is imposed. Since the BBR implies that debt can never go up, what we need to show is that for any $b \in\left(b_{0}, \widehat{b}\right]$ the probability that debt remains at $b$ goes to zero as $t$ goes to infinity.

Given an initial debt level $b \in\left[b_{0}, \widehat{b}\right]$, let $H^{m}\left(b, b^{\prime}\right)$ denote the probability that in $m$ periods debt will be less than $b^{\prime} \in\left[b_{0}, b\right]$ given the equilibrium debt policy function $b_{c}^{\prime}\left(b_{0}, A\right)$. Suppose that we could show that for any initial $b \in\left(b_{0}, \widehat{b}\right]$ there exists an $\varepsilon>0$ and an integer $m$ such that $H^{m}\left(b, b_{c}^{*}(b)\right)$ exceeds $\varepsilon$. Then we could conclude that for any $b \in\left(b_{0}, \widehat{b}\right]$ the probability that debt remains at $b$ goes to zero as $t$ goes to infinity. To prove this, choose any $b \in\left(b_{0}, \widehat{b}\right]$ and let $\varsigma>0$. Then we need to show that there exists some $t_{\varsigma}$ such that the probability that debt is equal to $b$ after $t_{\varsigma}$ periods is less than $\varsigma$. But we know that after $t \cdot m$ periods the probability that debt will equal $b$ will be less than $\left[1-H^{m}\left(b, b_{c}^{*}(b)\right)\right]^{t}<(1-\varepsilon)^{t}$. By choosing $t_{\varsigma}$ such that $(1-\varepsilon)^{t_{\varsigma} / m} \leq \varsigma$ we obtain the desired result.

We now establish:

Claim 1: For any $b \in\left(b_{0}, \widehat{b}\right]$, there exists an $\varepsilon>0$ and an integer $m$ such that $H^{m}\left(b, b_{c}^{*}(b)\right) \geq \varepsilon$.

Proof: For any $b \in\left[b_{0}, \widehat{b}\right]$ and $A \in[\underline{A}, \bar{A}]$ define the sequence $\left\langle\phi_{m}(b, A)\right\rangle_{m=1}^{\infty}$ inductively as follows: $\phi_{0}(b, A)=b$ and $\phi_{m+1}(b, A)=b_{c}^{\prime}\left(\phi_{m}(b, A), A\right)$. Thus, $\phi_{m}(b, A)$ is the equilibrium level of debt if the debt level were $b$ at time 0 and the shock was $A$ in periods 1 through $m$.

Recall that, by assumption, there exists some positive constant $\xi>0$, such that for any pair of realizations satisfying $A<A^{\prime}$, the difference $G\left(A^{\prime}\right)-G(A)$ is at least as big as $\xi\left(A^{\prime}-A\right)$. This implies that for any $b \in\left[b_{0}, \widehat{b}\right], H^{m}\left(b, \phi_{m}(b, \underline{A}+\lambda)\right)-H^{m}\left(b, \phi_{m}(b, \underline{A})\right) \geq \xi^{m} \lambda^{m}$ for all $\lambda$ such that $0<\lambda<\bar{A}-\underline{A}$. To see this, let $\mathbf{A}=\left(A_{1}, A_{2}, \ldots, A_{k}, \ldots\right)$ be a countable vector of shocks such that $A_{j} \in[\underline{A}, \underline{A}+\lambda]$ for all $j=1, \ldots, \infty$, and for all $m$ let $\mathbf{A}^{m}=\left(A_{1}, A_{2}, \ldots, A_{m}\right)$ be the list of the first $m$ elements. Define also the sequence $\left\langle\phi_{m}\left(b, \mathbf{A}^{m}\right)\right\rangle_{m=1}^{\infty}$ inductively as follows: $\phi_{1}\left(b, \mathbf{A}^{1}\right)=b_{c}^{\prime}\left(b, A_{1}\right)$ 
and $\phi_{k+1}\left(b, \mathbf{A}^{k+1}\right)=b_{c}^{\prime}\left(\phi_{k}\left(b, \mathbf{A}^{k}\right), A_{k+1}\right)$. Clearly $\phi_{1}\left(b, \mathbf{A}^{1}\right) \in\left(\phi_{1}(b, \underline{A}), \phi_{1}(b, \underline{A}+\lambda)\right)$. Assume that $\phi_{k}\left(b, \mathbf{A}^{k}\right) \in\left(\phi_{k}(b, \underline{A}), \phi_{k}(b, \underline{A}+\lambda)\right)$, then, since $b_{c}^{\prime}(b, A)$ is increasing in $b$ and $A$ :

$$
\begin{aligned}
\phi_{k+1}\left(b, \mathbf{A}^{k+1}\right) & \in\left(b_{c}^{\prime}\left(\phi_{k}(b, \underline{A}), A_{k+1}\right), b_{c}^{\prime}\left(\phi_{k}(b, \underline{A}+\lambda), A_{k+1}\right)\right. \\
& \subset\left(b_{c}^{\prime}\left(\phi_{k}(b, \underline{A}), \underline{A}\right), b_{c}^{\prime}\left(\phi_{k}(b, \underline{A}+\lambda), \underline{A}+\lambda\right)\right. \\
& =\left(\phi_{k+1}(b, \underline{A}), \phi_{k+1}(b, \underline{A}+\lambda)\right)
\end{aligned}
$$

It follows that $\phi_{k+1}\left(b, \mathbf{A}^{k+1}\right) \in\left(\phi_{k+1}(b, \underline{A}), \phi_{k+1}(b, \underline{A}+\lambda)\right)$. This implies that after $m$ periods, if the initial state is $b$ and if there are $m$ sequential shocks $A_{j} \in[\underline{A}, \underline{A}+\lambda]$, then debt will certainly be in $\left(\phi_{m}(b, \underline{A}), \phi_{m}(b, \underline{A}+\lambda)\right)$. The probability that after $m$ periods, if the initial state is $b$, debt is in $\left(\phi_{m}(b, \underline{A}), \phi_{m}(b, \underline{A}+\lambda)\right)$ must therefore be larger than the probability of $m$ sequential shocks $A_{j} \in[\underline{A}, \underline{A}+\lambda]$. This probability is at least $(\xi \lambda)^{m}$.

Given this, to prove the Claim it suffices to show that there exists an integer $m$ such that $A^{*}\left(\phi_{m}(b, \underline{A}), b_{c}^{*}(b)\right)>\underline{A}$. If this is the case by continuity there is a $\lambda_{m}(b)>0$ small enough such that $A^{*}\left(\phi_{m}\left(b, \underline{A}+\lambda_{m}(b)\right), b_{c}^{*}(b)\right)>\underline{A}$. It then follows that

$$
\begin{aligned}
H^{m}\left(b, b_{c}^{*}(b)\right) & =\int_{z} H^{1}\left(z, b_{c}^{*}(b)\right) d H^{m-1}(b, z) \\
& \geq \int_{\phi_{m}(b, \underline{A})}^{\phi_{m}\left(b, \underline{A}+\lambda_{m}(b)\right)} H^{1}\left(z, b_{c}^{*}(b)\right) d H^{m-1}(b, z) \\
& \geq H^{1}\left(\phi_{m}\left(b, \underline{A}+\lambda_{m}(b)\right), b_{c}^{*}(b)\right)\left[H^{m-1}\left(b, \phi_{m-1}\left(b, \underline{A}+\lambda_{m}(b)\right)\right)-H^{m-1}\left(b, \phi_{m-1}(b, \underline{A})\right)\right] \\
& \geq H^{1}\left(\phi_{m}\left(b, \underline{A}+\lambda_{m}(b)\right), b_{c}^{*}(b)\right)\left(\xi \lambda_{m}(b)\right)^{m-1}>0 .
\end{aligned}
$$

The third inequality follows from the facts that $H^{1}\left(b, b^{\prime}\right)$ is non-increasing in $b$ and $\phi_{m}(b, \underline{A}+$ $\left.\lambda_{m}(b)\right) \geq \phi_{m}(b, \underline{A})$.

It remains to show that there exists an integer $m$ such that $A^{*}\left(\phi_{m}(b, \underline{A}), b_{c}^{*}(b)\right)>\underline{A}$. Suppose, to the contrary, that for all $m$ we have that $A^{*}\left(\phi_{m}(b, \underline{A}), b_{c}^{*}(b)\right) \leq \underline{A}$. To simplify notation, let $\phi_{m}=\phi_{m}(b, \underline{A})$ for all $m$. The BBR implies that for all $m, \phi_{m-1} \geq \phi_{m}$. We can therefore assume without loss of generality that the sequence $\left\langle\phi_{m}\right\rangle$ converges to some finite limit $\phi_{\infty} \geq b_{0}$. Since $A^{*}\left(\phi_{m}, b_{c}^{*}(b)\right) \leq \underline{A}$ and $\phi_{m} \leq b$, we know that $G\left(A^{*}\left(\phi_{m}, b_{c}^{*}\left(\phi_{m}\right)\right)\right)=0$. Thus from (23) we have that for all $m$

$$
-\delta n E \frac{\partial v_{c}\left(\phi_{m}, A\right)}{\partial b}=\frac{\int_{\underline{A}}^{\min \left\{\bar{A}, \widehat{A}\left(\phi_{m}\right)\right\}}\left(\frac{1-\tau_{c}\left(\phi_{m}, A\right)}{1-\tau_{c}\left(\phi_{m}, A\right)(1+\varepsilon)}\right) d G(A)+\int_{\min \left\{\bar{A}, \widehat{A}\left(\phi_{m}\right)\right\}}^{\bar{A}}\left(\frac{1-\tau_{\phi_{m}}(A)}{1-\tau_{\phi_{m}}(A)(1+\varepsilon)}\right) d G(A)(1-\delta)}{1-\delta\left(1-G\left(\min \left\{\bar{A}, \widehat{A}\left(\phi_{m}\right)\right\}\right)\right.} .
$$


But we know that it must be the case that

$$
\frac{\tau_{c}\left(\phi_{m}, \underline{A}\right)}{1-\tau_{c}\left(\phi_{m}, \underline{A}\right)(1+\varepsilon)} \geq-\delta n E \frac{\partial v_{c}\left(\phi_{m+1}, A\right)}{\partial b}
$$

where the inequality is strict if the BBR is binding. This means that

$$
\frac{\tau_{c}\left(\phi_{m}, \underline{A}\right)}{1-\tau_{c}\left(\phi_{m}, \underline{A}\right)(1+\varepsilon)} \geq \frac{\int_{\underline{A}}^{\min \left\{\bar{A}, \widehat{A}\left(\phi_{m}\right)\right\}}\left(\frac{1-\tau_{c}\left(\phi_{m+1}, A\right)}{1-\tau_{c}\left(\phi_{m+1}, A\right)(1+\varepsilon)}\right) d G(A)+\int_{\min \left\{\bar{A}, \widehat{A}\left(\phi_{m}\right)\right\}}^{\bar{A}}\left(\frac{1-\tau_{\phi_{m}}(A)}{1-\tau_{\phi_{m}}(A)(1+\varepsilon)}\right) d G(A)(1-\delta)}{1-\delta\left(1-G\left(\min \left\{\bar{A}, \widehat{A}\left(\phi_{m}\right)\right\}\right)\right.}
$$

where the inequality is strict if the BBR is binding. Note however that if $\phi_{m+1}$ is sufficiently close to $\phi_{m}$ then since $\tau_{c}(b, A)$ and $\tau_{b}(A)$ are increasing in $A$ and

$$
1-\delta\left(1-G\left(\min \left\{\bar{A}, \widehat{A}\left(\phi_{m}\right)\right\}\right)\right)<1
$$

the right hand side must be strictly larger than the left hand side, a contradiction. We conclude therefore that for $m$ sufficiently large $A^{*}\left(\phi_{m}(b, \underline{A}), b_{c}^{*}(b)\right)>\underline{A}$, which yields the result.

The description of what the policies would be at the steady state debt level $b_{0}$ follows the characterization following Proposition 3.

\subsection{Proof of Proposition 6}

We first show that the average primary surplus at the steady state debt level $b_{0}$ is less than the average primary surplus in the long run in the unconstrained equilibrium. The primary surplus is the difference between tax revenues and spending on the public good and pork. In the unconstrained equilibrium, using the budget constraint, we may write this as $P S(b, A)=$ $(1+\rho) b-b^{\prime}(b, A)$. Let $E P S(b)=\int P S(b, A) d G(A)$. Let $H\left(b, b^{\prime}\right)$ be the transition function implied by the unconstrained equilibrium; that is, the probability that in the next period the initial level of debt will be less than or equal to $b^{\prime} \in\left[b^{*}, \bar{b}\right)$ if the current level is $b$. Let $\psi(b)$ denote the long run equilibrium debt distribution. This satisfies the condition that

$$
\psi\left(b^{\prime}\right)=\int_{b} H\left(b, b^{\prime}\right) d \psi(b) .
$$

(For the details see Battaglini and Coate (2008)). Then we have that the average primary surplus in the long run in the unconstrained equilibrium is

$$
\int_{b^{*}}^{\bar{b}} \operatorname{EPS}(b) d \psi(b)=(1+\rho) E(b)-\int_{b^{*}}^{\bar{b}} b^{\prime} d \psi\left(b^{\prime}\right)=\rho E(b)
$$


From Proposition 5, we know that the average primary surplus in the steady state under a strict BBR is just $\rho b_{0}$. We also know that $b_{0}<b^{*}$. Thus we have that

$$
\int_{b^{*}}^{\bar{b}} E P S(b) d \psi(b)=\rho E(b)>\rho b^{*}>\rho b_{0},
$$

as required.

We next show that the average level of pork-barrel spending at the steady state debt level $b_{0}$ is larger than the average amount of pork-barrel spending in the long run in the unconstrained equilibrium. By Proposition 5, average pork-barrel spending at the steady state debt level $b_{0}$ is given by

$$
\int_{\underline{A}}^{A^{*}\left(b_{0}, b_{0}\right)} B\left(\tau^{*}, g^{*}(A), b_{0}, b_{0}\right) d G(A) .
$$

Average pork-barrel spending in the long run in the unconstrained equilibrium is

$$
\int_{b^{*}}^{\bar{b}}\left\{\int_{\underline{A}}^{A^{*}\left(b, b^{*}\right)} B\left(\tau^{*}, g^{*}(A), b^{*}, b\right) d G(A)\right\} d \psi(b),
$$

where $\psi(b)$ is the invariant distribution. We have that

$$
\begin{aligned}
\int_{b^{*}}^{\bar{b}}\left\{\int_{\underline{A}}^{A^{*}\left(b, b^{*}\right)} B\left(\tau^{*}, g^{*}(A), b^{*}, b\right) d G(A)\right\} d \psi(b) & \leq \int_{\underline{A}}^{A^{*}\left(b^{*}, b^{*}\right)} B\left(\tau^{*}, g^{*}(A), b^{*}, b^{*}\right) d G(A) \\
& <\int_{\underline{A}}^{A^{\left(b_{0}, b_{0}\right)}} B\left(\tau^{*}, g^{*}(A), b_{0}, b_{0}\right) d G(A),
\end{aligned}
$$

where the last inequality follows from the fact that $b_{0}<b^{*}$.

\section{Appendix B}

\subsection{Computing the unconstrained equilibrium}

The characterization in Proposition 1 suggests a simple algorithm to compute the unconstrained equilibrium. Given a value of $b^{*},(8)$ is a functional equation that can be solved for the equilibrium value function $v(b, A)$. The equation has a unique solution since the mapping defined by the maximization on the right hand side of (8) is a contraction. The only difficulty is that the lower bound $b^{*}$ is endogenously determined along with the value function. However, this difficulty can be overcome by exploiting the fact that $b^{*}$ solves the maximization problem described in (7). 
These observations motivate the following computational procedure:

- Step 1. Choose some $z \in \mathcal{B}$ as a value for $b^{*}$ and obtain the values $\tau^{*}$ and $g^{*}(A)$ from equations (5) and (6) respectively.

- Step 2. Solve for $v_{z}$ by iterating on the value function below

$$
v_{z}(b, A)=\max _{\left(\tau, g, b^{\prime}\right)}\left\{\begin{array}{c}
u(\tau, g)+A \ln g+\frac{B\left(\tau, g, b^{\prime} ; b\right)}{n}+\delta E v_{z}\left(b^{\prime}, A^{\prime}\right) \\
B\left(\tau, g, b^{\prime} ; b\right) \geq 0, g \leq g^{*}(A), \tau \geq \tau^{*}, \& \quad b^{\prime} \in\left[z, b_{u}\right] .
\end{array}\right\}
$$

- Step 3. Calculate

$$
\arg \max \left\{b^{\prime} / q+\delta E v_{z}\left(b^{\prime}, A^{\prime}\right): b^{\prime} \in \mathcal{B}\right\}
$$

- Step 4. If the optimal value calculated in Step 3 is not $z$, select another $z \in \mathcal{B}$ as a value for $b^{*}$ and repeat the procedure. If the optimal value is $z$, then $z$ is the estimate of $b^{*}$ and $v_{z}$ is the estimated equilibrium value function. ${ }^{25}$ The equilibrium policy functions can then be obtained by solving the constrained planning problem described in Step 2.

Effectively, our computational procedure searches for a $b^{*}$ that is a fixed point of the above system. Intuitively, we are searching for the value of $b^{*}$ that determines a value function for which the mwc would actually choose to borrow $b^{*}$ when providing pork to its members.

In our numerical implementation, we use a 50-point grid $\mathcal{A}$ for the preference shocks. We choose the grid $\mathcal{B}$ for debt so that further increases in the number of points neither change the lower bound $b^{*}$ nor the value of the key statistics we attempt to match. The resulting set $\mathcal{B}$ has 950 non-evenly spaced grid points, which are more concentrated at values of debt greater than zero. A global approximation method is used in the computation of the equilibrium.

\subsection{Computing the constrained equilibrium}

The computation of the equilibrium is much easier with a strict BBR than without because the function $b_{c}^{*}(b)$ can be directly solved for. To see this, note that the steady state value of debt $b_{0}$ can be computed directly from equation (18), since the tax function $\tau_{b}(A)$ can be obtained by solving the static problem (16). Given this, the function $f(b)$ can be found immediately by

\footnotetext{
${ }^{25}$ In fact, once we obtain an approximated value for $b^{*}$, we refine the search by allowing the threshold $z$ to be a real number and use a bisection method to obtain a more accurate approximation (interpolating the expected value function using Chebyshev polynomials).
} 
solving the differential equation (19) with initial condition $f\left(b_{0}\right)=b_{0}$, and the end point $b_{1}$ can be found using equation $(20) \cdot{ }^{26}$ Once the function $b_{c}^{*}(b)$ is obtained, policy and value functions can be computed following Step 2 in the algorithm described above (with the exception that the constraint on debt is replaced by $\left.b^{\prime} \in\left[b_{c}^{*}(b), b\right]\right)$. For the calibrated economy, we find that $b_{0}=3.1$, a significantly lower value than $b^{*}$, which was 30.3 .

${ }^{26}$ We use a fourth-order Runge-Kutta method to solve for the differential equation. 